\title{
A Purkinje cell to parabrachial nucleus pathway enables broad cerebellar influence over the forebrain and emotional valence
}

\author{
Christopher H. Chen, Leannah N. Newman, Amanda P. Stark, Katherine E. Bond, Dawei Zhang, \\ Kefiloe Mutume, Isabella Flaquer, Wade G. Regehr*
}

\section{Department of Neurobiology, Harvard Medical School, Boston, MA 02115, USA}

*For correspondence: wade_regehr@hms.harvard.edu

\begin{abstract}
In addition to its well-known contributions to motor control and motor learning, the cerebellum is involved in language, emotional regulation, anxiety, and affect ${ }^{1-4}$. We found that suppressing the firing of cerebellar Purkinje cells (PCs) rapidly excites forebrain areas that could contribute to such functions, including the amygdala, basal forebrain, and septum, but that the classic cerebellar outputs, the deep cerebellar nuclei (DCN), do not project to these regions. Here we show that parabrachial nuclei (PBN) neurons that receive direct $\mathrm{PC}$ input, project to and influence all of these forebrain regions and many others. Furthermore, the function of this pathway is distinct from the canonical pathway: suppressing PC to PBN activity is aversive, whereas suppressing the PC to DCN pathway is rewarding. Therefore, the PBN pathway allows the cerebellum to influence the entire spectrum of valence, modulate the activity of forebrain regions known to regulate diverse nonmotor behaviors, and may be the substrate for many nonmotor disorders related to cerebellar dysfunction.
\end{abstract}

The posterior vermis of the cerebellar cortex has been implicated in many nonmotor behaviors. In animal models, disruption or stimulation of different regions of the vermis modulates aggression ${ }^{5}$, motor planning $^{6,7}$, spatial memory ${ }^{8-10}$, aspects of fear ${ }^{11-13}$, and hippocampal epilepsy ${ }^{14,15}$. In humans, damage to the vermis is associated with deficits in emotional control, language, memory, and executive function ${ }^{3,4}$. Cerebellar damage can also result in emotional disturbances consistent with limbic system dysfunction ${ }^{1,2}$.

It is not known how the posterior vermis influences these behaviors, but it seems likely that it somehow influences regions associated with them. Electrical stimulation of the cerebellum rapidly increases activity in the hypothalamus ${ }^{16,17}$, the amygdala ${ }^{17-19}$, basal forebrain ${ }^{17}$, septum ${ }^{17,19}$, hippocampus ${ }^{17-20}$, and specific regions of the cortex ${ }^{16-18}$. The interpretation of these results is complicated, because electrical stimulation can antidromically activate mossy fibers and other modulatory fibers.

To assess the influence of the posterior vermis of the cerebellum on other brain regions, we used optogenetics to selectively suppress spontaneous PC firing. This disinhibits PC targets, and is more selective than electrical stimulation. We briefly $(20 \mathrm{~ms})$ illuminated the posterior vermis through a 
thinned skull to suppress PC firing in awake head-restrained PCP2-cre/Halo mice, which selectively express halorhodopsin in PCs, and monitored activity in downstream regions with multielectrode arrays. This approach was minimally invasive, but had the disadvantage that light attenuation limited the speed and the extent of PC inhibition ${ }^{21}$.

As expected, suppression of PC spiking evoked large, short-latency increases in spiking in the thalamus, a known monosynaptic target of DCN neurons (Figure 1A-B). In an example cell, inhibition of PC activity initially elevated thalamic firing from $10 \mathrm{~Hz}$ to $70 \mathrm{~Hz}$ with a $12 \mathrm{~ms}$ latency for about $30 \mathrm{~ms}$, which was followed about $50 \mathrm{~ms}$ later by another increase in activity (Supplemental Figure 1A). Similar responses were seen in 62\% (54/87) of thalamic neurons (Figure 1B, top). The locations of responding cells (Figure 1B, right) were consistent with previous anatomical descriptions of DCN projections $^{22-24}$. The latencies (28 $\pm 1 \mathrm{~ms}$ average) and amplitudes (4.2 \pm 1.0 -fold mean increase) of evoked responses were highly variable (Supplemental Figure 1EF).

PC suppression also increased spiking in other brain regions of interest. In the amygdala, PC suppression evoked spiking in $41 \%$ (30/73) of recorded neurons with a latency of $33.4 \pm 1.8 \mathrm{~ms}$ and a $2.8 \pm 0.7$-fold increase in firing rate (Figure 1B, Supplemental Figure 1B). In the septum, $60 \%$ of the neurons responded to PC suppression (Figure 1B, Supplemental Figure 1C). Firing rates rapidly increased in most neurons $(54 \%, 37 / 68,33 \pm 2 \mathrm{~ms}$ latency and 3.0 \pm 0.5 -fold increase in firing rate). A few cells responded later with a significant pause in activity $(6 \%, 4 / 68)$ with a latency of $42 \pm 6$ ms. Finally, in the basal forebrain, $21 \%(18 / 86)$ of the cells were excited with a latency of $23.3 \pm 2.8 \mathrm{~ms}$ and a $2.0 \pm 0.3$ fold increase in firing rate, and $31 \%(27 / 86)$ of the cells were inhibited with a latency of $20 \pm 2 \mathrm{~ms}$ (Figure 1B, Supplemental Figure 1D-F).

These results establish that suppressing PC firing in the cerebellar vermis rapidly elevates firing in the thalamus, the amygdala, the septum, and the basal forebrain with comparable magnitudes and latencies. We also find that some cells in the septum and basal forebrain can be rapidly suppressed by cerebellar inhibition. Whereas the monosynaptic DCN excitation of the thalamus is well established, it is unclear how reducing PC activity elevates activity in the amygdala, the septum and the basal forebrain. The temporal resolution of this approach and the overall latency of about $30 \mathrm{~ms}$ from cerebellar inhibition to forebrain response does not exclude the involvement of additional intermediate brain regions or synapses.

To provide insight into the direct synaptic inputs to these regions of interest with the hope of clarifying the cerebellar pathway, we injected cholera toxin subunit $\beta$, a retrograde tracer, into the thalamus $(\mathrm{n}=$ $9)$, amygdala $(n=9)$, basal forebrain $(n=4)$, and septum $(n=5)$ (Figure 1C). Several days later, we sliced sections to determine the injection site (Figure 1D), and sectioned the cerebellum and brain stem to identify retrogradely labelled cells (Figure 1E-F). In these experiments, cholera toxin variants that led to the expression of different color fluorophores were used so that different brain regions could be injected in the same animal.

As expected, thalamic injections retrogradely labelled many neurons in the contralateral DCN, and labelled few cells in the ipsilateral DCN, which is consistent with the well described direct DCN to thalamus pathway ${ }^{22-24}$. On the other hand, injections into the amygdala, basal forebrain and the septum did not show any retrograde labelling in either the contralateral or ipsilateral DCN (Figure 1E, G). Instead, injections into the amygdala and basal forebrain led to prominent labelling of the ipsilateral PBN, and some labeling of the contralateral PBN (Figure 1E, G). Similar results were seen for injections into the septum, although the close proximity of the septum to the midline made it difficult to restrict injections to just one side of the septum and to determine the extent to which the PBN projection to the septum is ipsilateral or contralateral. Thalamic injections also prominently labelled the ipsilateral PBN, and weakly labelled the contralateral PBN (Figure 1E, G). 
The labelling of the PBN is intriguing because some PCs in the vermis directly synapse within the $\mathrm{PBN}^{25-28}$. However, there had been no indication that the PC to PBN output pathway allows the cerebellum to influence the forebrain, and it was thought that this projection primarily controls autonomic functions like heart rate and respiration through descending projections from the PBN ${ }^{25-28}$. Nonetheless, because some regions of the PBN project to the forebrain ${ }^{29}$, and the PBN is implicated in behaviors that might be related to cerebellar dysfunction ${ }^{30-32}$, we hypothesized that the PC to PBN pathway has extensive influence over forebrain function.

To begin to test this hypothesis and investigate PC-PBN connectivity, we next determined which regions of the cerebellar cortex project to the PBN by injecting retrobeads into the PBN. Selective injections into the PBN labelled PCs in the posterior lobules, VIII-X (Figure 2A-B). The highest density of retrogradely labelled PCs was found $0.56 \pm 0.06 \mathrm{~mm}$ from the midline (Figure 2C), ipsilateral to the injection site. This indicates that many PCs in the vermis, particularly the posterior vermis, project to the PBN.

To determine the extent of PC synapses in the PBN, we used PCP2-cre/Synaptophysin-tdTomato mice to fluorescently label all presynaptic boutons made by PCs. Synaptophysin-tdTomato fluorescence and the brightfield image were used to identify the PBN, which surrounds the superior cerebellar peduncle (Figure 2D, G). We compared the densities of PC synapses in the PBN with the density in the DCN and the vestibular nuclei (VN), areas known to be strongly inhibited by PCs. Remarkably, the density of PC boutons in the PBN is comparable to the density within the VN. As expected, the density of PC boutons in the DCN is significantly higher than both (Figure 2E, F). These studies indicate that PC synapses are dense in the PBN, suggesting that PCs inhibit PBN neurons. Moreover, PC synapses are widely distributed, are not restricted to a particular subregion of the $\mathrm{PBN}$, and exhibit some regional heterogeneity. In the coronal plane, PC synapses are present at higher densities on the medial side of the brachium, and with respect to the anterior-posterior axis PC synapses are largely absent from the most anterior regions (Figure 2H). The widespread but heterogeneous distribution of PC synapses within the PBN suggests that the cerebellum may regulate many, but not all, PBN-dependent behaviors.

We tested the functional properties of PC inhibition of neurons in the PBN both in vivo and in vitro. We suppressed PC firing in vivo in PCP-cre/halorhodopsin mice using an approach that was similar to

Figure 1 (Figure 2I, Supplemental Figure 2B), and found that firing was elevated in $68 \%$ of PBN neurons, with a short latency in 47\% (Figure 2J, Supplemental Figure 2C, F) and a long latency in $21 \%$ of them (Supplemental Figure 2D, F). In similar experiments for DCN neurons, firing was evoked in all DCN neurons with a short-latency (<30 ms) (Supplemental Figure 2E,F). There was no secondary elevation of activity within the DCN, where recurrent excitation has not been described. These results suggest that in contrast to the DCN where all cells are powerfully inhibited by PCs, only about half of the cells in the PBN are directly inhibited by PCs. The long-latency responses evoked in $21 \%$ of PBN neurons suggest that these neurons are not directly inhibited by PCs, but they may be disynaptically excited by other PBN neurons. These findings suggest that PCs directly inhibit approximately half of the cells in the PBN, and that these cells recurrently excite other PBN neurons.

We also characterized the PC to PBN neuron synapse in acute coronal PBN brain slices. We used PCP2cre/ChR2 mice and optically stimulated PCs while blocking excitatory synaptic transmission and measured large $(1.8 \pm 0.5 \mathrm{nA})$, short latency $(2.33 \pm 0.13 \mathrm{~ms})$ IPSCs in 9 of 12 PBN neurons (Figure 2KL). These recordings suggest that PCs provide large monosynaptic inhibitory connections to approximately $75 \%$ of the neurons in the posterior PBN.

To comprehensively determine how the cerebellum-PBN pathway could influence the forebrain, we used an anatomical transynaptic approach to label PBN neurons that receive direct PC inhibition. We 
injected AAV1-syn-Cre, a trans-synaptic, anterograde virus that induces cre-expression in target neurons ${ }^{33}$, into the posterior vermis, and injected both AAV-flex-tdTomato and AAV-synaptophysinYFP into the PBN (Figure 3A). This method leads to tdTomato labelling that is restricted to PBN neurons targeted by PCs, and can be used to visualize their axons. YFP and tdTomato will co-label on the presynaptic boutons associated with these axons. This approach provides specificity but only labels a small fraction of PBN neurons targeted by PCs due to the limited efficiency of trans-synaptic Cre labelling, and because we only targeted the posterior cerebellum.

We used this approach to examine the regions studied in experiments shown in Figure 1. tdTomato positive axons with synaptophysin-YFP labelled boutons were found in the amygdala, basal forebrain, and septum (Figure 3B-D, Supplemental Figure 3), indicating that cerebellar-recipient PBN neurons project directly to these regions.

To assess the functional role of the PC to PBN pathway it is necessary to specifically target the PC to PBN projection. Illumination of the posterior vermis is not sufficiently selective because it also suppresses firing in PCs that project to the DCN and VN. Similarly, if the same PCs project to the PBN, DCN, and VN, optical activation of ChR2-expressing PC fibers that project to the PBN with also affect some PC synapses in the DCN and the VN. We therefore determined whether inhibition of PC axons expressing halorhodopsin might be a solution. We placed an optrode into the PBN and simultaneously recorded single-unit activity while locally illuminating halorhodopsin-expressing PC axons. Brief illumination (100 ms) evoked rapid $(5.8 \pm 0.9 \mathrm{~ms}), 1.5$-fold $(1.5+0.1)$ increases in firing (Figure 3E-F, H, Supplemental Figure 4A-B) in 17/31 cells. This was significantly shorter than the latency of responses in Figure 2.

To directly test the effect of the cerebellum-PBN pathway on downstream regions, we performed experiments similar to those of Figure 1, but here we optically suppressed PC axons within the PBN. We restricted our single-unit recordings to the septum (Figure 3E, G-J, Supplemental Figure 4C-D), because optical fiber implants in the PBN impede recording from more posterior regions of the forebrain. Halorhodopsin activation evoked large (2.7 \pm 0.6 -fold) short latency $(21.6 \pm 2.1 \mathrm{~ms})$ increases in firing rate in 17/40 septal neurons.

It was impractical to record from cells in regions more posterior than the septum because of the optical fiber used to illuminate the PBN, but we were able to use the immediate early gene c-Fos as an alternative reporter of activity ${ }^{34,35}$. We unilaterally illuminated PC axons in the PBN (100 ms pulse every $8 \mathrm{~s}$ ) for three hours before removing their brains and staining for c-Fos (Figure 3I), in Cre+ mice $(n=4)$, and in Cre- control mice $(n=4)$. Stimulation elevated c-Fos near the optical fiber in the PBN in Cre+ mice (Figure 3J). c-Fos staining was not elevated relative to control animals in the contralateral $\mathrm{PBN}$, the locus coeruleus (a region with high rates of spontaneous firing), or in either the ipsilateral or contralateral DCN and VN (Figure 3J-K, P, Supplemental Figure 5A-B). Interestingly, c-Fos labelling was low in the DCN and VN of both Cre+ and Cre- mice, but was significantly lower in Cre+ animals (Figure 3P). Although this approach provides a means of selectively suppressing PC inhibition in the PBN, it generally leads to activation of a rather small fraction of PBN cells near the tip of the optical fiber.

Activation of the cerebellum to PBN pathway elevated cFos labelling in many forebrain regions. c-Fos levels were increased in the ipsilateral amygdala, the ipsilateral basal forebrain, and the lateral septum (Figure 3P). c-Fos levels were not elevated in the medial septum of Cre+ mice relative to Cre- animals (Figure 3P), which contrasts with our observation that suppression of the PC to PBN pathway increases firing in the medial septum (Figure 3G). It is possible that high c-Fos levels present in the medial septum in control mice obscure stimulus-induced increases in c-Fos in Cre+ mice. We also quantified 
stimulus-induced changes in c-Fos levels in other forebrain regions, as informed by our anatomical studies. We observed axonal labelling and stimulus-induced increases in c-Fos levels in the ipsilateral cingulate cortex, piriform cortex, and hypothalamus (Figure 3L-O, P, Supplemental Figure 5C). For all of these regions there was more c-Fos expression in ipsilateral regions than in either contralateral regions or in Cre-animals.

Previous studies of the PC-PBN projection suggested that its primary role was in the control of the autonomic system ${ }^{26,36-38}$. We tested this by bilaterally suppressing PC to PBN inhibition in awake mice using a protocol $(5 \mathrm{~s}, 10 \mathrm{~Hz}, 50 \mathrm{~ms}$ illumination) that elevates PBN activity (Figure 4A, Supplemental Figure 6). Suppressing PC to PBN synapses led to pupil dilation, which is a measure of arousal, but, surprisingly, it did not modulate heart rate (Figure 4B). We also examined the effects of suppressing PC to DCN synapses and found that it led to an even larger pupil dilation, and to a small increase in heart rate (Figure 4B, normalized PBN heart rate: $1.02 \pm 0.01$; DCN: $1.12 \pm 0.08$ S.E.M.). The observation that PC-PBN suppression did not affect heart rate was surprising, and was not consistent with this being a primary role of this pathway.

The PBN is a heterogeneous region known to be involved in numerous behaviors, and in most cases activation of the PBN is aversive ${ }^{39,40}$. In contrast, the $\mathrm{DCN}$ is implicated in reward ${ }^{41}$. We therefore performed place-preference tests to compare the effects of optogenetically suppressing PC inputs to these regions using optical fibers placed in either the PB or the DCN (Figure 4A). Prior to performing place preference tests, we characterized the effects of suppressing PC inputs. Suppressing either the PBN pathway or the DCN pathway did not promote movement (Supplemental Figure 7). We then tested the effects of suppressing the two cerebellar output pathways in a real-time place preference protocol (Figure 4C-E). On Day 1, mice were placed in an arena with two chambers for 15 minutes. On Day 2, the $10 \mathrm{~Hz}, 50 \mathrm{~ms}$ pulses stimuli (Supplemental Figure 6) was delivered whenever mice entered the bottom chamber, and ceased when they left the chamber. On Day 3, no stimulus was delivered so mice could be tested for any memory of Day 2's stimuli. On Day 4, the stimulus was delivered when the mice entered the top chamber, to determine if any preference remaining on Day 3 could be reversed.

Suppressing the PC-PBN pathway on Day 2 led to aversion $(0.36 \pm 0.02$, fraction time spent in the bottom chamber, S.E.M.) compared to Day $1(0.53 \pm 0.02)$. In contrast, following suppression of the PCDCN pathway on Day 2, mice preferred the stimulated chamber $(0.67 \pm 0.08)$, in contrast to Day $1(0.47$ $\pm 0.03)$. Preferences were maintained on Day 3 for PBN implanted animals $(0.40 \pm 0.03)$, but were not maintained for DCN implanted animals $(0.52 \pm 0.04)$. PBN-implanted mice did not show a preference during the reversal trial on Day $4(0.50 \pm 0.03)$. Wildtype animals never showed a preference during the same protocol (Figure 4G). Experiments in which a single optical fiber targeted either the PBN or the DCN pathway showed similar, but weaker preferences (Supplemental Figure 8).

Our main finding is that the PC to PBN output pathway provides a means for the cerebellum to influence many forebrain regions that are involved in diverse nonmotor behaviors. We find that the cerebellum has a much more extensive and powerful influence on the PBN than had been previously appreciated. We find that brief optogenetic suppression of PC spiking in the posterior vermis or suppression of PC synapses within the PBN disinhibits more than half of posterior PBN neurons, and causes them to spike rapidly. This suggests that PCs, which fire spontaneously in vivo from $20-120 \mathrm{~Hz}$, provide ongoing suppression of spiking within the PBN. The observation that brief inhibition of PC firing often elicited a secondary wave of activity within the PBN suggests that recurrent excitatory connections within the PBN may further amplify the effects of cerebellar activity.

One of the most distinctive features of the cerebellar output pathway through the PBN is that it projects extensively throughout the forebrain, whereas the conventional PC to DCN pathway does not (Figure 4H-I). We established this through trans-synaptic anterograde tracing, c-Fos, and in vivo 
electrophysiology. These targets include many brain regions not normally associated with cerebellar function, motor performance or motor learning, such as the amygdala, basal forebrain, cingulate cortex and the septum. The PC-PBN pathway provides a long sought-after explanation for the many studies that suggested the cerebellum plays an important role in emotional regulation, possibly through a direct cerebellar pathway to limbic regions ${ }^{16-20}$. Our place preference experiments indicate that disinhibition of the PC-PBN pathway is aversive where disinhibition of the PC-DCN pathway is rewarding. This allows the cerebellum full control over the entire spectrum of valence, where previous work only demonstrated the cerebellum's role in reward ${ }^{41}$.

In principle, the PC-PBN pathway may inhibit many of the functions of the PBN. Subsets of cells in the PBN are associated with a number of functions ranging from general arousal/wakefulness ${ }^{42,43}$, danger encoding $^{30}$, fear $^{32,39}$, and feeding ${ }^{44,45}$. We conclude that the PC-PBN pathway may signal aversion, but the approach we use in this study is constrained: by inhibiting all PC-PBN inputs we do not distinguish between postsynaptic cells, their functions, their spatial locations, and their projection targets. Moreover, it is unlikely that we are unable to completely inhibit PC axons using halorhodopsin ${ }^{46,47}$, and thus our behavioral and functional results are underestimates of their full effects.

Damage to the posterior cerebellum causes symptoms consistent with the function of PC-PBN projection targets. Cerebellar Cognitive Affective Syndrome (CCAS) is a syndrome resulting from damage (genetic or otherwise) to the posterior lobules of the cerebellum ${ }^{3}$. These symptoms include disturbances in affect, emotional control, arousal, and executive function, and correspond very well with known roles of the regions targeted by PC-PBN outputs that we describe here. The basal forebrain plays an important role in affect, the amygdala is critical for emotional control, activity in the septum correlates with arousal, and the cingulate cortex is a part of the prefrontal, executive cortices. In contrast, the DCN do not have direct projections to these regions. Thus, the PC-PBN pathway is well suited to playing an essential role in behaviors associated with CCAS.

The posterior cerebellum and the PC-PBN pathway is also particularly sensitive to concussive injury $^{48,49}$, in particular the cerebellar lobules lining the $4^{\text {th }}$ ventricle. Traumatic brain injury can also damage the tracts of the superior cerebellar peduncle, where the cerebellar axons course through and the cells of the PBN reside. This type of damage is most commonly associated with PTSD and anxiety disorders ${ }^{50}$. Both of these conditions are tightly linked to the downstream structures in the PC-PBN pathway.

In addition to CCAS and PTSD, clinicians have more broadly observed cerebellar associations with sleep disturbances ${ }^{51}$, anxiety ${ }^{52}$, schizophrenia ${ }^{53-55}$, and mood disorders ${ }^{56}$. The PC-PBN pathway provides multiple avenues for the cerebellum to influence the limbic system and associated neurological disorders.

\section{Materials \& Methods:}

\section{Animals used}

For injection of retrograde and anterograde tracers (cholera toxin,retrobeads, and AAVs), male and female C57BL/6J mice (Jackson labs) were used. For in vivo electrophysiology and behavior, male and female B6.Cg-Tg(Pcp2-cre)3555Jdhu/J x B6;129S-Gt(ROSA)26Sor ${ }^{\text {tm 39(CAG-hop/EYFP)Hze } / J ~(P C P 2-c r e ~ x ~}$ Halorhodopsin, Jackson Labs) were used. For the anatomical tracing studies, male and female B6.Cg$T g(P c p 2-c r e) 3555 J d h u / J$ x B6;129S-Gt(ROSA)26Sor ${ }^{\text {tm34.1(CAG-Syp/tdTomato)Hze } / J(P C P 2-c r e ~ x ~}$ synaptophysin-tdTomato, Jackson Labs) were used. All animals were used under supervision of Harvard 
Medical School's Institutional Animal Care and Use Committee (IACUC). We used the Mouse Brain in Stereotaxic Conditions Atlas ${ }^{57}$ as a reference for surgical coordinates.

\section{General Surgery Protocol}

Mice were anesthetized and maintained under $2 \%$ isoflurane. Mice were secured to a Stereotaxic Surgery Instrument (Model 940 Small Animal, Kopf Instruments, Tujunga, CA). Eye ointment was applied and reapplied throughout surgery as needed. The heads of the mice were sanitized with an alcohol-coated wipe, after which the hair on the surgical area was removed with Nair. The exposed skin of the head was then sanitized with betadine solution. An incision was made to expose the cranium, and the surgery would proceed with the injection or implantation. Incisions were closed with sutures or dental cement (MetaBond, Parkell). Mice were injected with slow-release buprenorphine for analgesia and monitored for the next three days for post-op care.

\section{Preparation of mice for in vivo recordings \& modulation of PCs}

Mice were implanted with a custom-made titanium head bracket and the cranium above the cerebellum and the recording areas of interest was exposed. During surgery, the skull above the cerebellum was thinned using a handheld drill until the underlying region of the brain was visible. After every pass with the drill, ACSF was dripped onto the skull to avoid thermal damage to surface neurons. At the end of the surgery, all areas exposed were covered with silicone elastiomer (Kwik-Sil, World Precision Instruments). Mice were allowed to recover from surgery for at least three days. For acclimation, the mouse was head restrained over a free-moving wheel for 30 minutes every day for 3 days until the first day of recording.

This preparation minimally perturbed cerebellar tissue and enabled us to stimulate a large area (approximately $3 \mathrm{~mm}$ in diameter) over multiple recording sessions, and has several advantages over electrical stimulation, which has been used in previous studies. It takes advantage of the fact that PCs fire spontaneously at high frequency, and suppressing this activity leads to rapid disinhibition that evokes rapid increases in firing of downstream neurons. In addition, because halorhodopsin is restricted to PCs, it specifically manipulates just those neurons, and not fibers of passage as in electrical stimulation.

\section{In vivo electrophysiology}

Mice were anesthetized with $2 \%$ isoflurane. Next, a craniotomy was drilled over the recording site in accordance with the coordinates determined for the desired brain area. After the mouse had awoken, at least two hours later, single-unit, multielectrode recordings were made with a silicon probe (P or E-style 16 channel probes, Cambridge NeuroTech) dipped in Di-I (Vybrant Multicolour Cell Labelling Kit, Thermofisher) while the mouse was head restrained over a freely rotating wheel. This procedure was repeated the next day for a maximum of three days of recording per mouse. Once recordings were done, mice were perfused with PBS and 4\% PFA. 100 um coronal slices were made from the brain tissue to determine electrode placement.

Optrodes were either constructed by gluing a $100 \mu \mathrm{m}$ optical fiber $(0.22 \mathrm{NA}$, Thorlabs $)$ to a silicon probe (P or E-style 16 channel probes, Cambridge Neurotech) or custom-ordered from Cambridge Neurotech (P-style 16 channel probe with a Lambda-B tapered optical fiber attached).

\section{Optical stimulation}

An MRL-III-635L Diode Red 635 nm Laser (Opto Engine LLC, Midvale, UT) was used to activate halorhodopsin for all experiments. For experiments involving inhibiting PC soma through the thinned 
cranium, the beam was widened such that it encompassed the entire thinned region - the posterior vermis and paravermis. Steady state power density from the laser was measured to be $\sim 80 \mathrm{~mW} / \mathrm{mm}^{2}$. For experiments involving implanted optical fibers or optrodes, the steady-state intensity of light was $\sim 25 \mathrm{~mW}$, as measured from the tip of the optical component prior to implantation or insertion.

\section{In Vivo Recording \& Analysis}

Data were sampled at $20 \mathrm{kHz}$ using an RHD2000 recording system (Intan Technologies). Data was filtered between 0.1 and 8kHz. Data were sorted using Plexon Offline Sorter (Plexon Inc, Texas). Further analysis was all done in MATLAB (Mathworks, MA). Peri-stimulus firing rate histograms were generated from these spike times. Excitation or inhibition was defined as an increase/decrease of the smoothed firing rate (6 ms window) 2 standard deviations from the baseline firing rate after stimulus onset.

\section{Slice Electrophysiology}

Slices were made from adult (>P40) B6.Cg-Tg(Pcp2-cre)3555Jdhu/J x B6;129S-

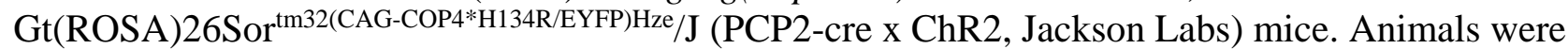
anesthetized with isoflurane and transcardially perfused with solution composed of in $\mathrm{mM}$ : 110 Choline $\mathrm{Cl}, 2.5 \mathrm{KCl}, 1.25 \mathrm{NaH}_{2} \mathrm{PO}_{4}, 25 \mathrm{NaHCO}_{3}, 25$ glucose, $0.5 \mathrm{CaCl}_{2}, 7 \mathrm{MgCl}_{2}, 3.1 \mathrm{Na}$ Pyruvate, $11.6 \mathrm{Na}$ Ascorbate, 0.002 (R,S)-CPP, 0.005 NBQX, oxygenated with $95 \% \mathrm{O} 2 / 5 \% \mathrm{CO}_{2}$, and kept at $35^{\circ} \mathrm{C} .200$ $\mu \mathrm{m}$ thick coronal slices were cut (Leica $1200 \mathrm{~S}$ vibratome) and transferred to a chamber with ACSF (in mM: $127 \mathrm{NaCl}, 2.5 \mathrm{KCl}, 1.25 \mathrm{NaH}_{2} \mathrm{PO}_{4}, 25 \mathrm{NaHCO}_{3}, 25$ glucose, $1.5 \mathrm{CaCl}_{2}, 1 \mathrm{MgCl}_{2}$ ). Slices were allowed to recover at $35^{\circ} \mathrm{C}$ for at least $20 \mathrm{~min}$ before experiments.

Borosilicate electrodes (2-4 M $\Omega$ ) were filled with internal solution (in mM: $110 \mathrm{CsCl}, 10 \mathrm{HEPES}, 10$ TEA-Cl, $1 \mathrm{MgCl}_{2}, 4 \mathrm{CaCl}_{2}$, 5 EGTA, 20 Cs-BAPTA, 2 QX314, 0.2 D600, $\mathrm{pH}$ to 7.3). All experiments were performed at $32-35^{\circ} \mathrm{C}$ in $5 \mu \mathrm{M}$ NBQX to block AMPARs, and $2.5 \mu \mathrm{M}(\mathrm{R})-\mathrm{CPP}$ to block NMDARs. Cells were held at $-60 \mathrm{mV}$. PC axons expressing ChR2 were stimulated by $473 \mathrm{~nm}$ light from an LED (Thorlabs) th through a 60x objective for full-field illumination. Single $1 \mathrm{~ms}$ pulses $\left(\sim 80 \mathrm{~mW} / \mathrm{mm}^{2}\right.$ steady-state power density as measured under objective) were used.

\section{Viral Injections}

A hole was drilled at the desired medial-lateral (ML) and anterior-posterior (AP) coordinates for injection (Nanoject III, Drummond Scientific). The glass micropipette was placed $100 \mu \mathrm{m}$ below the dorsal-ventral (DV) coordinate to create a "pocket" for the substance to be distributed. To minimize labelling of the injection tract, injections proceeded slowly $(<10 \mathrm{nl} / \mathrm{s})$, and the pipette was left in place for at least 5 minutes following injection. Afterwards, the pipette was raised $100 \mu \mathrm{m}$ and set in place for another 5 minutes to ensure that the substance was deposited at the injection site. After this, the micropipette was slowly retracted from the brain tissue.

\section{Retrobead Injections}

$100 \mathrm{nl}$ of green retrobeads (Lumafluor) were injected into the parabrachial nucleus. Injections were made at a 22 degree angle (parallel to the longitudinal axis of the animal, angled with respect to the dorsal-ventral axis), at coordinates AP -3.725, ML 1.35, and -3.65 mm from the surface of the brain. After 3 days, mice were heavily anesthetized, perfused with PBS $+4 \%$ PFA, and their cerebellums were removed for histology. Sagittal slices of $50 \mu \mathrm{m}$ were made. Injection sites were scrutinized for leakage into the neighboring vestibular nuclei, or into the cerebellum itself. Any mistargeted injections were not included in further analysis. Only the two slices with the most labelled 
PCs were manually counted. These slices were most often found 0.5-0.6 $\mathrm{mm}$ from the midline of the cerebellum. Slices were imaged on the Zeiss Imager 2 Fluorescent Microscope.

\section{Choleratoxin injections}

Wildtype mice were injected with $200 \mathrm{~nL}$ cholera toxin subunit B (CTB) in the thalamus (CTB488; AP 1.22, ML 1, DV -4-3.5 mm), amygdala (CTB594; AP -1.3, ML 3.1, DV -4.3), and basal forebrain (CTB647; AP 0.14, ML 1.5, DV -5.5) or septum (CTB647; AP 1.1, ML 0, DV -3-4). One week later, mice were transcardially perfused with PBS and 4\% PFA. The brain was removed and left to post-fix in $4 \%$ PFA overnight. Next, $50 \mu \mathrm{m}$ sections were prepared using a vibratome and placed onto slides. The slices were carefully examined for any spillover into alternate forebrain regions, and those which were found to have spillover were excluded from further analysis. Images of the DCN and PBN were imaged on the Zeiss Imager 2 Fluorescent Microscope.

\section{Quantification of PC synaptophysin-tdTomato puncta in the brainstem}

PCP2-cre mice were crossed with a synaptophysin-tdTomato reporter line to visualize PC boutons in the parabrachial nucleus. Mice were heavily anesthetized, perfused with PBS+4\% PFA, and had their brains removed. After post-fixing for one day in PFA, brains were sliced coronally at $50 \mu \mathrm{m}$ for confocal imaging (Olympus FV1200). Large areas around the parabrachial nuclei ( 2 $\mathrm{mm}$ x $2 \mathrm{~mm}$ ) were imaged under a $60 \mathrm{X}$ objective by acquiring multiple overlapping fields and stitching them together in ImageJ's Grid/Collection stitching plugin. These areas were manually matched and aligned to corresponding DIC brightfield images of the same regions using the cerebellar lobules and the $4^{\text {th }}$ ventricle as guides. The brachium was segmented manually from the DIC image (see Figure 2G), as was the cerebellum. Puncta from the confocal image were segmented using the MatBots toolbox ${ }^{58}$ in particular the Nuclei Segmentation Bot. In brief, two slices were manually annotated for puncta and used to train a general model to annotate the entire dataset. Once puncta were identified, locations were remapped onto the annotated brightfield image. The model was not trained to differentiate tdTomato in the axon bouton from signals in PC somata and dendrites. Therefore, the cerebellum was not included in further analysis. All analysis was conducted in MATLAB.

\section{Quantification and visualization of cerebellar-recipient parabrachial neuron projections in the forebrain}

Wildtype mice were injected with 100-200 nl AAV1-Syn-Cre (AAV.hSyn.Cre.WPRE.hGH, Addgene) in the posterior cerebellum (AP -7.2, DV -2-3, ML 0), and 100-200 nl cre-dependent tdTomato (AAV2/1.FLEX.tdTomato.WPRE.SV40, Addgene) and synaptophysin-YFP (AAV8.2-hEF1asynaptophysin-EYFP, MGH Vector Core) in the parabrachial nucleus (22 degree angle, AP -7.2, DV3.65, ML, 1.35). After waiting two to three weeks, mice were heavily anesthetized, perfused with PBS and $4 \%$ PFA, and had their brains removed. After post-fixing for one day in PFA, brains were sliced coronally at $50 \mu \mathrm{m}$.

Slices of the entire brain were imaged with the whole slide scanner (Olympus VS120). For two animals in the septum, amygdala, and basal forebrain, three slices were selected, and three areas of $0.5 \mathrm{~mm} \times 0.5$ $\mathrm{mm}$ x $5 \mu \mathrm{m}$ were imaged using a confocal microscope (Olympus FV1200) under a 60X objective with a z-increment of $1 \mu \mathrm{m}$ steps. To image the entire $0.5 \mathrm{~mm} \times 0.5 \mathrm{~mm}$ field, four overlapping fields were acquired and stitched them together in ImageJ's Grid/Collection stitching plugin.

Puncta from the confocal image were segmented using the Nuclei Segmentation Bot in MatBots ${ }^{58}$. Small areas from each field in the septum, basal forebrain, and amygdala were annotated to train a general model for each area. These models of each forebrain region were then used to segment the entire dataset. The $\mathrm{z}$-stack was max projected to generate a $2 \mathrm{~d}$ image without losing any puncta. 
The number of synaptophysin puncta overlapping with tdTomato labelled axons indicates the density of PC recipient parabrachial axonal projections to these forebrain regions. To find the overlap of synaptophysin puncta and tdTomato signal, first the tdTomato signal was thresholded two standard deviations away from the average pixel intensity. Then, the overlap of segmented synaptophysin puncta on top of the tdTomato axon signal was quantified. Because these were max projections of $5 \mu \mathrm{m} \mathrm{z}$ stacks, we accounted for the fraction of synaptophysin puncta that would overlap tdTomato signal by chance. The total area of synaptophysin signal was divided by the total area of tdTomato signal, and this percentage was subtracted from the measured overlap. For reference, this percentage was exceedingly low $(<0.1 \%)$.

The Volume Annotation Bot in MatBots ${ }^{58}$ was used to fully reconstruct several axons in each area to more carefully examine the overlap of synaptophysin on tdTomato axon signal for several select regions. Multiple slices from the complete $20 \mu \mathrm{m}$ stack image were manually annotated to train models to automate the reconstructions of the axons across the entire stack. Similar manual annotations were done to identify synaptophysin puncta. Once axons and synaptophysin were segmented, all boutons that did not overlap axons were removed from the 3D reconstructions to more easily visualize axons from cerebellum-recipient parabrachial neurons (Supplemental Figure 3).

\section{Implantation of Bilateral Optical Fibers and EMG wires}

Following the general surgical protocol (above), two 000-120 x 1/16" screws (Antrin Miniature Specialties, Fallbrook, CA) secured to the skull to stabilize further implants. Two teflon coated tungsten wires (de-insulated $1 \mathrm{~mm}$ from implanted end, $100 \mu \mathrm{m}$ diameter, A-M Systems, Sequim, WA) were implanted superficially under the skin along each side of the mouse's back for EMG measurements. Then, a custom-made ( $4.5 \mathrm{~mm}$ long with $1.7 \mathrm{~mm}$ separation) two ferrule dual fiber-optic cannula (Doric lenses, Canada) was implanted at a $22^{\circ}$ angle away from the skull at AP -3.72, ML \pm 1.35 , and DV -3.6 for PBN implants or AP -4.72, ML -1.35, and DV -2.9 for DCN implants. Metabond Quick Adhesive Cement (Parkell, Edgewood, NY) was applied to secure the fiber optic and the custom-made titanium head bracket. The mice were then removed from the stereotaxic surgery apparatus, placed in new cage, and allowed to recover for at least 2 days.

\section{Quantification of c-Fos labelling in the parabrachial nucleus, cerebellum, and forebrain} PCP2cre/Halo and wildtype mice were implanted with fiber optics in the parabrachial nucleus as discussed above (22 degree angle, AP -7.2, DV-3.65, ML, 1.35). Awake head-fixed mice were stimulated with $100 \mathrm{~ms}$ pulses unilaterally every 8 seconds for 3 hours. They were then rapidly anesthetized, perfused with PBS+4\% PFA, and had their brains removed. After post-fixing for one day in PFA, brains were sliced either coronally or sagittally at $50 \mu \mathrm{m}$ for imaging. For brains sliced coronally, a DiI coated pin was inserted to indicate the stimulated side. The slices were stained for c-Fos (1:500 dilution, \#2250, Cell Signaling) and visualized with the Alexa 647 secondary antibody (1:500 dilution, ab150083, Abcam). Slices of the entire brain were imaged with the whole slide scanner (Olympus VS120). These slide scanner images were then manually matched and aligned to identify the regions noted in Figure 3. For quantification, two randomly selected areas of $500 \mu \mathrm{m} \times 500 \mu \mathrm{m}$ were chosen in each brain region of interest in six slices from each of four animals on each side of the brain. Cells were counted blind to condition, and regions were selected blind to c-Fos fluorescence.

\section{Pupil Dilation, EMG Measurement, and Wheel Movement}

Pupils were imaged using a USB camera (Mako U-029B, Edmund Optics) acquiring at 300-330 Hz. The camera was controlled and the pupil diameter was measured online using custom scripts in MATLAB. 
Signals from implanted wires were amplified using a modified Backyard Brains Spikerbox ${ }^{59}$. Wheel movement was tracked using a disassembled optical mouse and the Arduino Uno microcontroller. Signals were routed to the analog input channels on a RHD2000 recording system (Intan Technologies). EMG signals were then bandpass filtered offline (1-500 Hz) for analysis. Heart beats were isolated first by bandpassing the EMG signal $(5-200 \mathrm{~Hz})$ and then manually sorting cardiac potentials in Offline Sorter (Plexon).

\section{Place Preference}

Implanted mice were handled by experimenters for at least 15 minutes prior to any procedures to acclimate them to handling. Mice were subsequently acclimated to a Branching Fiber-optic Splitter wire (Doric lenses, Quebec City, QC, Canada) attached to their implanted optical fibers for 1 hour in a 46" by 46" box. The wire was attached to a 1x1 Fiber-optic Rotary Joint (Doric lenses, Quebec City, QC, Canada) which was connected to the $635 \mathrm{~nm}$ laser.

Place preference testing occurred in a two chambered box with visual landmarks in each chamber and a doorway between the chambers. This testing chamber was housed in a behavioral testing closet with white noise $(60 \mathrm{~dB})$ and illumination at 30 lumens. Place preference testing consisted of 15 -minute trials (baseline: no stimulus assigned, test: bottom chamber assigned stimulus, retention: no stimulus assigned, and reversal: top chamber assigned stimulus) that took place over 4 consecutive days. Mice were tracked online with a custom MATLAB script and a USB camera (ELP USB with Camera 2.1mm Lens, ELP, China). Continuous $50 \mathrm{~ms} 10 \mathrm{~Hz}$ pulses were delivered when mice entered the assigned stimulus chamber, and ceased when they left. Mice that were found to have a significant initial preference for either chamber in the baseline test (Percent Time > 70\%) were excluded from analysis.

\section{Confirmation of Implant Locations}

PCP2-cre/Halo mice and wildtype were perfused with PBS and 4\% PFA. After perfusion, the brains were removed and allowed to post-fix in 4\% PFA overnight. After the post-fixing period, the 4\% PFA was replaced with PBS. Each brain was sliced sagittally at $100 \mathrm{um}$ in PBS and cover-slipped. All mice with correct bilateral implants in either PBN or DCN were included in the initial analysis shown in Figure 4. We subsequently analyzed mice where only one implant was correctly located in either the PBN or DCN and the other implant was located outside either region, and show that data in

Supplemental Figure 8. All bilateral parabrachial nucleus implants and bilateral DCN implants were within the same medial lateral plane $( \pm 100 \mu \mathrm{m})$.

\section{Behavioral Blinding}

For the first 36 mice, behavioral testing was carried out blind to genotype (PCP2-cre/Halo or wildtype) and optical fiber implant locations. Wildtypes were not included in the remaining 14 mice, though given that precise optical fiber implant locations were unknown until histology, experiments were blind to condition.

\section{Data Availability}

The data that support the findings of this study are available from the corresponding author upon reasonable request

\section{Author Contributions}

C.H.C. and W.G.R. conceived of the project. C.H.C, L.N.N., A.P.S., K.E.B, and W.G.R designed experiments. C.H.C., L.N.N., A.P.S. and D.Z. performed and analyzed in vivo electrophysiology experiments. C.H.C. performed in vitro slice electrophysiology experiments. C.H.C., L.N.N., A.P.S., 
and I.F. performed and analyzed anatomical tracing experiments. C.H.C., A.P.S., and K.E.B conducted and analyzed c-Fos functional anatomy experiments. C.H.C, K.E.B., K.M., and L.N.N. performed and analyzed behavioral experiments. C.H.C. and W.G.R wrote the paper with inputs from all authors.

\section{Acknowledgements}

We thank members of the Regehr lab and David Ginty for comments on the manuscript. This work was supported by grants from the NIH, R01NS032405 and R35NS097284 to W.G.R, K99NS110978 and F32NS101889 to C.H.C., and NINDS P30 Core Center (NS072030) to the Neurobiology Imaging Center at Harvard Medical School.

\section{Competing Interests}

The authors declare no competing interests

\section{References}

1 Hoche, F., Guell, X., Vangel, M. G., Sherman, J. C. \& Schmahmann, J. D. The cerebellar cognitive affective/Schmahmann syndrome scale. Brain 141, 248-270, doi:10.1093/brain/awx317 (2018).

2 Schmahmann, J. D. Disorders of the cerebellum: ataxia, dysmetria of thought, and the cerebellar cognitive affective syndrome. J Neuropsychiatry Clin Neurosci 16, 367-378, doi:10.1176/jnp.16.3.367 (2004).

3 Schmahmann, J. D. \& Sherman, J. C. The cerebellar cognitive affective syndrome. Brain 121 ( Pt 4), 561-579, doi:10.1093/brain/121.4.561 (1998).

4 Stoodley, C. J. \& Schmahmann, J. D. Functional topography in the human cerebellum: a metaanalysis of neuroimaging studies. Neuroimage 44, 489-501, doi:10.1016/j.neuroimage.2008.08.039 (2009).

5 Jackman, S. L. et al. Cerebellar Purkinje cell activity modulates aggressive behavior. Elife 9 , doi:10.7554/eLife.53229 (2020).

6 Chabrol, F. P., Blot, A. \& Mrsic-Flogel, T. D. Cerebellar Contribution to Preparatory Activity in Motor Neocortex. Neuron 103, 506-519 e504, doi:10.1016/j.neuron.2019.05.022 (2019).

7 Gao, Z. et al. A cortico-cerebellar loop for motor planning. Nature 563, 113-116, doi:10.1038/s41586-018-0633-x (2018).

8 Rochefort, C. et al. Cerebellum shapes hippocampal spatial code. Science 334, 385-389, doi:10.1126/science.1207403 (2011).

9 Zeidler, Z., Hoffmann, K. \& Krook-Magnuson, E. HippoBellum: Acute Cerebellar Modulation Alters Hippocampal Dynamics and Function. J Neurosci 40, 6910-6926, doi:10.1523/JNEUROSCI.0763-20.2020 (2020).

10 Joyal, C. C. et al. Effects of midline and lateral cerebellar lesions on motor coordination and spatial orientation. Brain Res 739, 1-11, doi:10.1016/s0006-8993(96)00333-2 (1996).

11 Apps, R. \& Strata, P. Neuronal circuits for fear and anxiety - the missing link. Nat Rev Neurosci 16, 642, doi:10.1038/nrn4028 (2015).

12 Frontera, J. L. et al. Bidirectional control of fear memories by cerebellar neurons projecting to the ventrolateral periaqueductal grey. Nat Commun 11, 5207, doi:10.1038/s41467-020-18953-0 (2020).

13 Vaaga, C. E., Brown, S. T. \& Raman, I. M. Cerebellar modulation of synaptic input to freezingrelated neurons in the periaqueductal gray. Elife 9, doi:10.7554/eLife.54302 (2020).

14 Krook-Magnuson, E., Szabo, G. G., Armstrong, C., Oijala, M. \& Soltesz, I. Cerebellar Directed Optogenetic Intervention Inhibits Spontaneous Hippocampal Seizures in a Mouse Model of Temporal Lobe Epilepsy. eNeuro 1, doi:10.1523/ENEURO.0005-14.2014 (2014). 
15 Streng, M. L. \& Krook-Magnuson, E. Excitation, but not inhibition, of the fastigial nucleus provides powerful control over temporal lobe seizures. J Physiol 598, 171-187, doi:10.1113/JP278747 (2020).

16 Anand, B. K., Malhotra, C. L., Singh, B. \& Dua, S. Cerebellar projections to limbic system. J Neurophysiol 22, 451-457, doi:10.1152/jn.1959.22.4.451 (1959).

17 Whiteside, J. A. \& Snider, R. S. Relation of cerebellum to upper brain stem. J Neurophysiol 16, 397-413, doi:10.1152/jn.1953.16.4.397 (1953).

18 Heath, R. G. \& Harper, J. W. Ascending projections of the cerebellar fastigial nucleus to the hippocampus, amygdala, and other temporal lobe sites: evoked potential and histological studies in monkeys and cats. Exp Neurol 45, 268-287, doi:10.1016/0014-4886(74)90118-6 (1974).

19 Snider, R. S. \& Maiti, A. Cerebellar contributions to the Papez circuit. J Neurosci Res 2, 133146, doi:10.1002/jnr.490020204 (1976).

20 Newman, P. P. \& Reza, H. Functional relationships between the hippocampus and the cerebellum: an electrophysiological study of the cat. The Journal of Physiology 287, 405-426, doi:10.1113/jphysiol.1979.sp012667 (1979).

21 Stujenske, J. M., Spellman, T. \& Gordon, J. A. Modeling the Spatiotemporal Dynamics of Light and Heat Propagation for In Vivo Optogenetics. Cell Rep 12, 525-534, doi:10.1016/j.celrep.2015.06.036 (2015).

22 Oh, S. W. et al. A mesoscale connectome of the mouse brain. Nature 508, 207-214, doi:10.1038/nature13186 (2014).

23 Kebschull, J. M. et al. Cerebellar nuclei evolved by repeatedly duplicating a conserved cell-type set. Science 370, doi:10.1126/science.abd5059 (2020).

24 Fujita, H., Kodama, T. \& du Lac, S. Modular output circuits of the fastigial nucleus for diverse motor and nonmotor functions of the cerebellar vermis. Elife 9, doi:10.7554/eLife.58613 (2020).

25 Hashimoto, M. et al. Anatomical Evidence for a Direct Projection from Purkinje Cells in the Mouse Cerebellar Vermis to Medial Parabrachial Nucleus. Front Neural Circuits 12, 6, doi:10.3389/fncir.2018.00006 (2018).

26 Nisimaru, N. Cardiovascular modules in the cerebellum. Jpn J Physiol 54, 431-448, doi:10.2170/jjphysiol.54.431 (2004).

27 Nisimaru, N. \& Katayama, S. Projection of cardiovascular afferents to the lateral nodulus-uvula of the cerebellum in rabbits. Neurosci Res 21, 343-350, doi:10.1016/0168-0102(94)00872-d (1995).

28 Nisimaru, N. et al. Orexin-neuromodulated cerebellar circuit controls redistribution of arterial blood flows for defense behavior in rabbits. Proc Natl Acad Sci U S A 110, 14124-14131, doi:10.1073/pnas.1312804110 (2013).

29 Saper, C. B. \& Loewy, A. D. Efferent connections of the parabrachial nucleus in the rat. Brain Res 197, 291-317, doi:10.1016/0006-8993(80)91117-8 (1980).

30 Campos, C. A., Bowen, A. J., Roman, C. W. \& Palmiter, R. D. Encoding of danger by parabrachial CGRP neurons. Nature 555, 617-622, doi:10.1038/nature25511 (2018).

31 Palmiter, R. D. The Parabrachial Nucleus: CGRP Neurons Function as a General Alarm. Trends Neurosci 41, 280-293, doi:10.1016/j.tins.2018.03.007 (2018).

32 Han, S., Soleiman, M. T., Soden, M. E., Zweifel, L. S. \& Palmiter, R. D. Elucidating an Affective Pain Circuit that Creates a Threat Memory. Cell 162, 363-374, doi:10.1016/j.cell.2015.05.057 (2015).

33 Zingg, B. et al. AAV-Mediated Anterograde Transsynaptic Tagging: Mapping Corticocollicular Input-Defined Neural Pathways for Defense Behaviors. Neuron 93, 33-47, doi:10.1016/j.neuron.2016.11.045 (2017). 
34 Morgan, J. I., Cohen, D. R., Hempstead, J. L. \& Curran, T. Mapping patterns of c-fos expression in the central nervous system after seizure. Science 237, 192-197, doi:10.1126/science.3037702 (1987).

35 Sheng, M. \& Greenberg, M. E. The regulation and function of c-fos and other immediate early genes in the nervous system. Neuron 4, 477-485, doi:10.1016/0896-6273(90)90106-p (1990).

36 Bradley, D. J., Ghelarducci, B., La Noce, A. \& Spyer, K. M. Autonomic and somatic responses evoked by stimulation of the cerebellar uvula in the conscious rabbit. Exp Physiol 75, 179-186, doi:10.1113/expphysiol.1990.sp003392 (1990).

37 Paton, J. F. \& Spyer, K. M. Brain stem regions mediating the cardiovascular responses elicited from the posterior cerebellar cortex in the rabbit. $J$ Physiol 427, 533-552, doi:10.1113/jphysiol.1990.sp018186 (1990).

38 Sadakane, K., Kondo, M. \& Nisimaru, N. Direct projection from the cardiovascular control region of the cerebellar cortex, the lateral nodulus-uvula, to the brainstem in rabbits. Neurosci Res 36, 15-26, doi:10.1016/s0168-0102(99)00103-0 (2000).

39 Bowen, A. J. et al. Dissociable control of unconditioned responses and associative fear learning by parabrachial CGRP neurons. Elife 9, doi:10.7554/eLife.59799 (2020).

40 Chiang, M. C. et al. Divergent Neural Pathways Emanating from the Lateral Parabrachial Nucleus Mediate Distinct Components of the Pain Response. Neuron 106, 927-939 e925, doi:10.1016/j.neuron.2020.03.014 (2020).

41 Carta, I., Chen, C. H., Schott, A. L., Dorizan, S. \& Khodakhah, K. Cerebellar modulation of the reward circuitry and social behavior. Science 363, doi:10.1126/science.aav0581 (2019).

$42 \mathrm{Xu}, \mathrm{Q}$. et al. Medial Parabrachial Nucleus Is Essential in Controlling Wakefulness in Rats. Front Neurosci 15, 645877, doi:10.3389/fnins.2021.645877 (2021).

43 Kaur, S. et al. Glutamatergic signaling from the parabrachial nucleus plays a critical role in hypercapnic arousal. J Neurosci 33, 7627-7640, doi:10.1523/JNEUROSCI.0173-13.2013 (2013).

44 Campos, C. A., Bowen, A. J., Schwartz, M. W. \& Palmiter, R. D. Parabrachial CGRP Neurons Control Meal Termination. Cell Metab 23, 811-820, doi:10.1016/j.cmet.2016.04.006 (2016).

45 Wu, Q., Clark, M. S. \& Palmiter, R. D. Deciphering a neuronal circuit that mediates appetite. Nature 483, 594-597, doi:10.1038/nature10899 (2012).

46 Kaneda, K. et al. Selective optical control of synaptic transmission in the subcortical visual pathway by activation of viral vector-expressed halorhodopsin. PLoS One 6, e18452, doi:10.1371/journal.pone.0018452 (2011).

47 Mahn, M., Prigge, M., Ron, S., Levy, R. \& Yizhar, O. Biophysical constraints of optogenetic inhibition at presynaptic terminals. Nat Neurosci 19, 554-556, doi:10.1038/nn.4266 (2016).

48 Park, E., Ai, J. \& Baker, A. J. Cerebellar injury: clinical relevance and potential in traumatic brain injury research. Prog Brain Res 161, 327-338, doi:10.1016/S0079-6123(06)61023-6 (2007).

49 Mac Donald, C. L. et al. Detection of blast-related traumatic brain injury in U.S. military personnel. N Engl J Med 364, 2091-2100, doi:10.1056/NEJMoa1008069 (2011).

50 Vasterling, J. J., Verfaellie, M. \& Sullivan, K. D. Mild traumatic brain injury and posttraumatic stress disorder in returning veterans: perspectives from cognitive neuroscience. Clin Psychol Rev 29, 674-684, doi:10.1016/j.cpr.2009.08.004 (2009).

51 DelRosso, L. M. \& Hoque, R. The cerebellum and sleep. Neurol Clin 32, 893-900, doi:10.1016/j.ncl.2014.07.003 (2014).

52 Moreno-Rius, J. The cerebellum in fear and anxiety-related disorders. Prog Neuropsychopharmacol Biol Psychiatry 85, 23-32, doi:10.1016/j.pnpbp.2018.04.002 (2018).

53 Andreasen, N. C. \& Pierson, R. The role of the cerebellum in schizophrenia. Biol Psychiatry 64, 81-88, doi:10.1016/j.biopsych.2008.01.003 (2008). 
54 Mothersill, O., Knee-Zaska, C. \& Donohoe, G. Emotion and Theory of Mind in SchizophreniaInvestigating the Role of the Cerebellum. Cerebellum 15, 357-368, doi:10.1007/s12311-0150696-2 (2016).

55 Picard, H., Amado, I., Mouchet-Mages, S., Olie, J. P. \& Krebs, M. O. The role of the cerebellum in schizophrenia: an update of clinical, cognitive, and functional evidences. Schizophr Bull 34, 155-172, doi:10.1093/schbul/sbm049 (2008).

56 Adamaszek, M. et al. Consensus Paper: Cerebellum and Emotion. Cerebellum 16, 552-576, doi:10.1007/s12311-016-0815-8 (2017).

57 Paxinos, G. \& Franklin, K. B. J. The mouse brain in stereotaxic coordinates. Compact 2nd edn, (Elsevier Academic Press, 2004).

58 Cicconet, M., Hochbaum, D. R., Richmond, D. L. \& Sabatin, B. L. in 2017 IEEE International Conference on Computer Vision Workshop (ICCVW). 134-142 (IEEE).

59 Marzullo, T. C. \& Gage, G. J. The SpikerBox: a low cost, open-source bioamplifier for increasing public participation in neuroscience inquiry. PLoS One 7, e30837, doi:10.1371/journal.pone.0030837 (2012). 
A

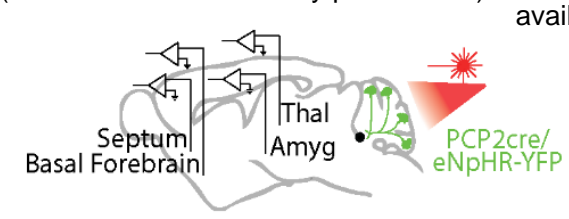
available under acC-BY-NC-ND 4 pternatipinal license.

B
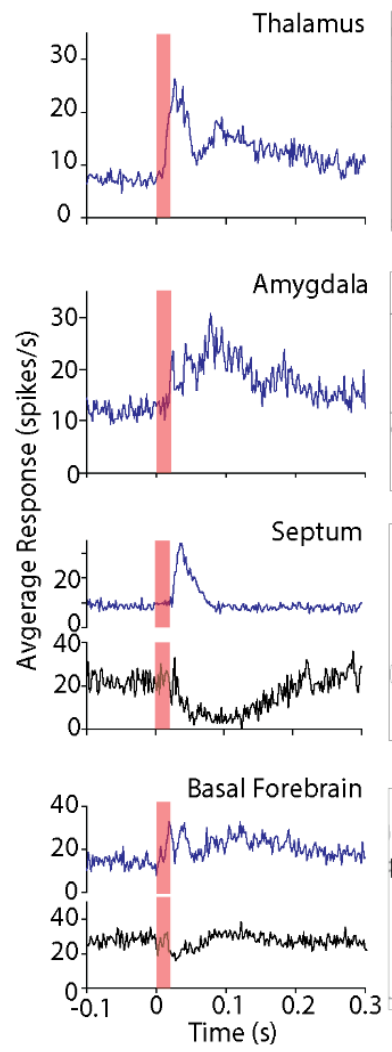

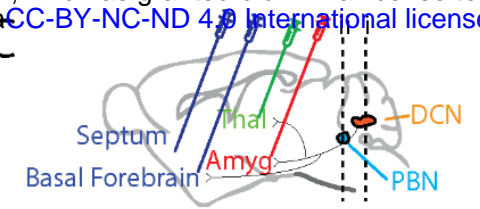

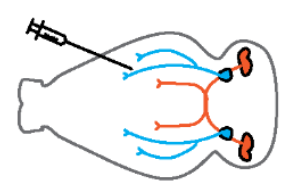

$\mathrm{E}$

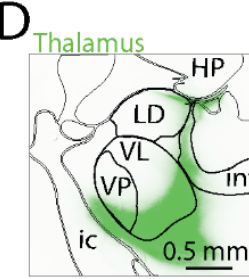

$0 . \underline{5 \mathrm{~mm}}$
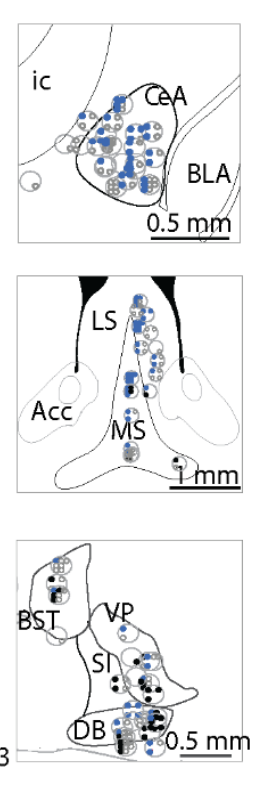
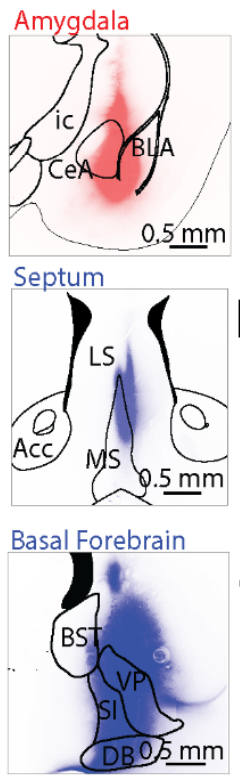

E Slice i (DCN)
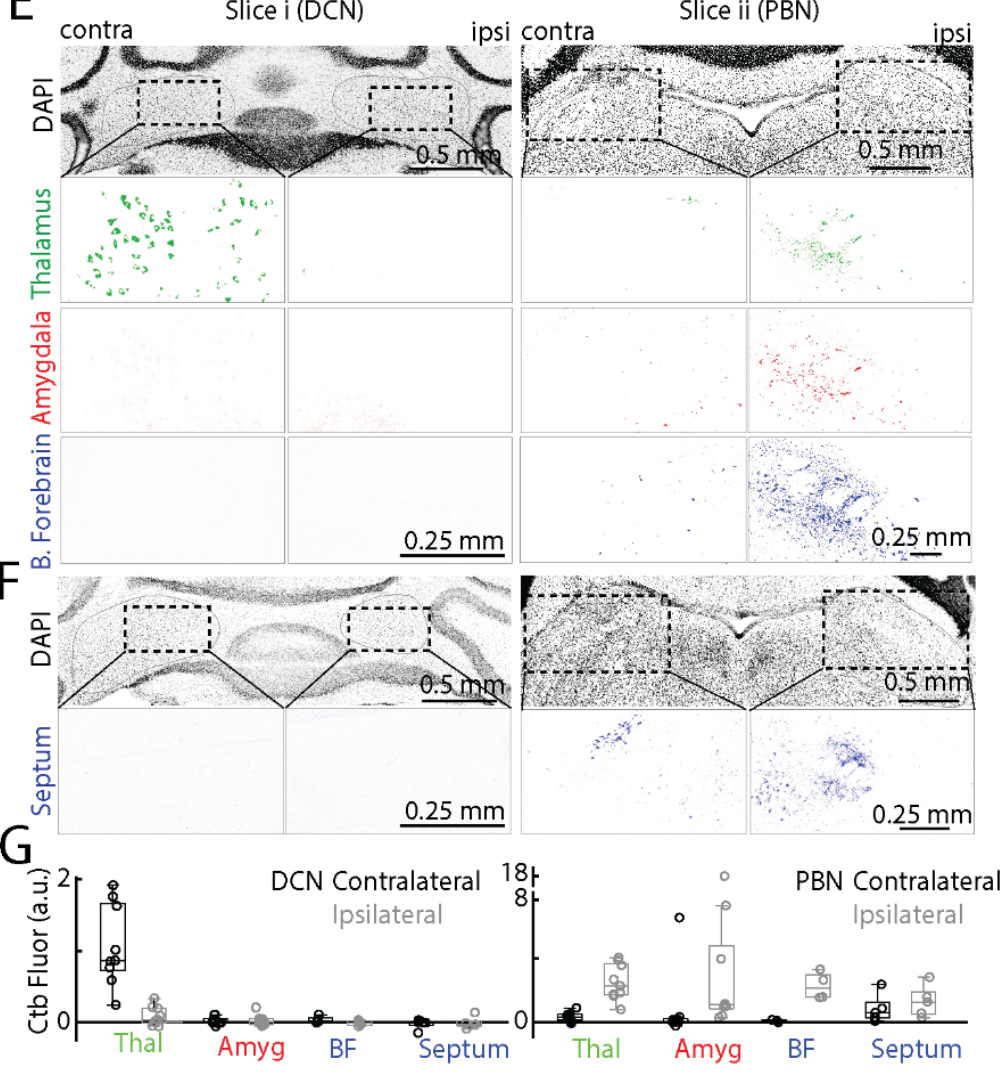

Figure 1: Suppressing Purkinje cell firing evoked short latency responses in multiple brain regions that are directly innervated by the PBN but not the DCN

A. Single-unit, multielectrode array recordings were made from awake, head-restrained PCP2Cre/Halo mice across several areas in the brain. 20 ms pulses of light were delivered to the posterior cerebellum.

B. Average increases in activity from recordings in the thalamus (54/87 responding neurons), amygdala (30/37), septum (37/68), and basal forebrain (18/86) are shown in blue. Decreases in activity (black) were seen in the septum (4/68) and basal forebrain (27/86). Recording sites are indicated in the grey circles within the corresponding panels on the right. Blue dots indicate responding cells at each site, black dots indicated cells with pauses in firing after stimulation, and open circles indicate nonresponding cells.

C. (Left) Retrograde tracer cholera toxin subunit B (Ctb) labelled with different color fluorophores was unilaterally injected into the thalamus, amygdala, basal forebrain, or septum. (Right) The deep cerebellar nuclei (DCN) and parabrachial nuclei (PBN) were then examined for retrograde labelling.

D. Injection sites are shown for thalamus, amygdala, and basal forebrain done in a single animal, and for the septum in a different animal

E. Retrograde labelling in the DCN and PBN is shown for an animal with three injections sites in $\mathbf{D}$.

F. Retrograde labelling in the DCN and PBN for the animal with septum injection site in $\mathbf{D}$

G. Quantification of retrograde labelling (Ctb fluorescence - background fluorescence) observed following injections into the indicated regions: thalamus injections $(n=9)$, amygdala $(n=9)$, basal forebrain $(n=4)$, and septal injections $(n=5)$.

LD: laterodorsal, VL: ventrolateral, VP: ventral posterior, int: intralaminar thalamus, ic: internal capsule, CeA: central amygdala, BLA: basolateral amygdala, LS: Lateral septum, MS: medial septum, Acc: nucleus accumbens, BST: bed nucleus of the stria terminalis, VP: ventral pallidum, SI: substantia innominate, and DB: diagonal band of broca 
bioRxiv preprint doi: https://doi.org/10.1101/2021.09.21.461236; this version posted September 23, 2021. The copyright holder for this preprint (which was not certified by peer review) is the author/funder, who has granted bioRxiv a license to display the preprint in perpetuity. It is made
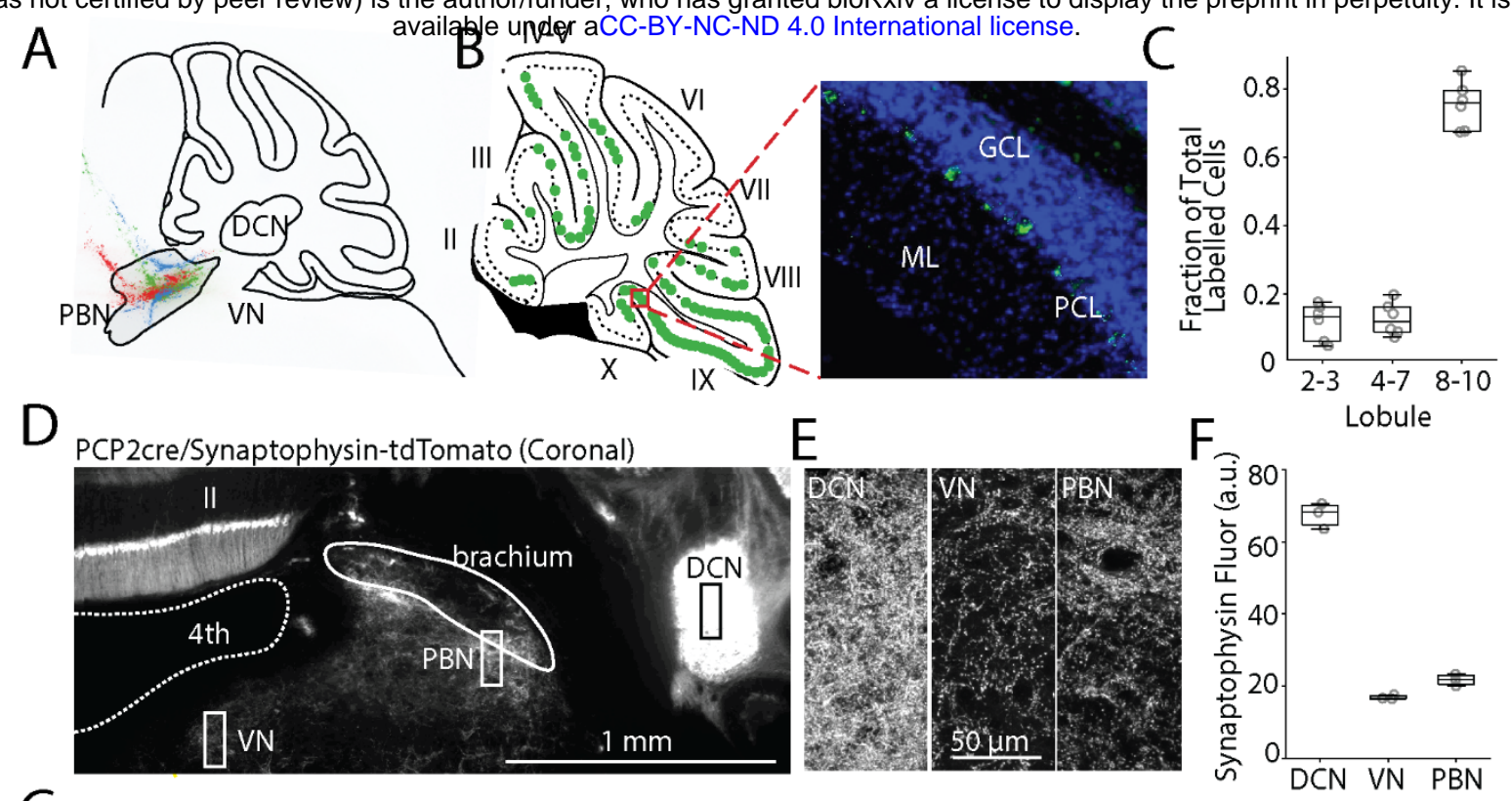

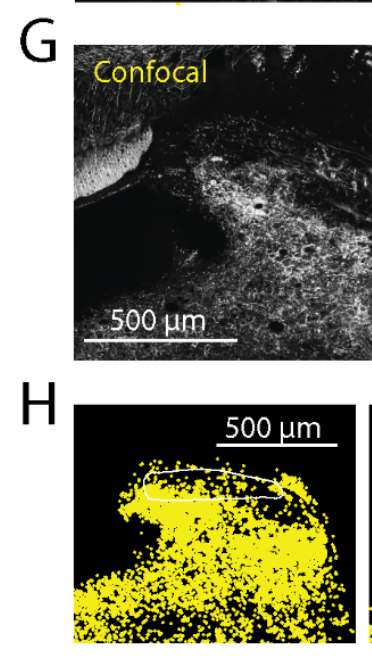

$-5.6 \mathrm{~mm}$

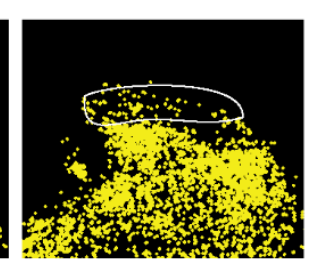

$-5.55 \mathrm{~mm}$
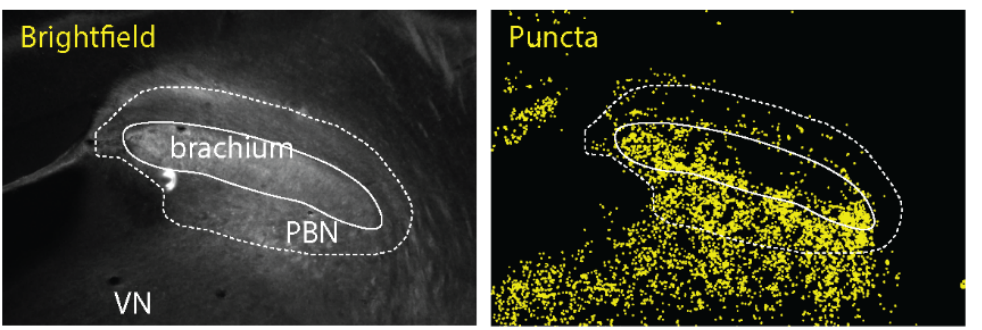

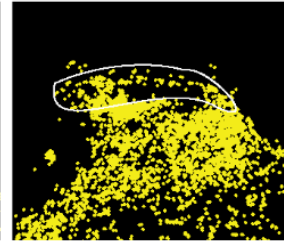

$-5.5 \mathrm{~mm}$

Distance from Bregma

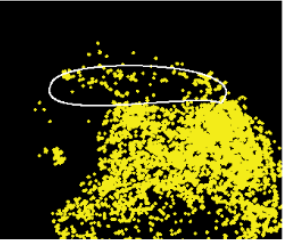

$-5.45 \mathrm{~mm}$

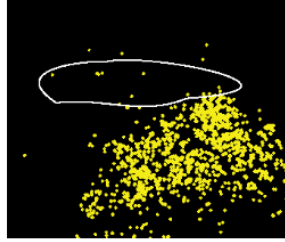

$-5.4 \mathrm{~mm}$
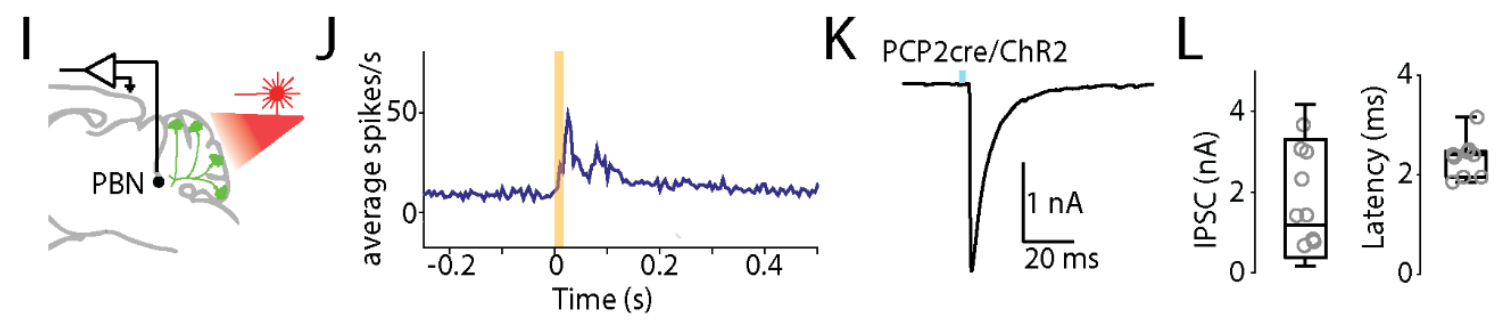

Figure 2: Purkinje cells make numerous synapses within the parabrachial nuclei

A. Fluorescent retrograde beads were injected into the PBN (noted in grey). Each injection is annotated in a different color. DCN: deep cerebellar nuclei, VN: vestibular nuclei, II-X: cerebellar lobules 2-10.

B. left, Retrogradely labelled cells from one injection are indicated in green.

right, Image of retrobead fluorescence (green) and DAPI labelling (blue). GCL: granular layer; PCL: Purkinje cell layer; ML: molecular layer.

C. Fraction of total labelled Purkinje cells in the indicated lobules.

D. PCP2-Cre Synaptophysin-tdTomato mice were used to label PC presynaptic boutons, although some somatic and dendritic labelling was also present. Strong labelling was observed in DCN, the VN and the PBN. 4th: 4th Ventricle; II: Lobule II of the cerebellar cortex.

E. Fluorescence images of regions in the DCN, VN, and PBN as indicated in D.

F. Quantification of the fluorescence signal in indicated regions. 
bioRxiv preprint doi: https://doi.org/10.1101/2021.09.21.461236; this version posted September 23, 2021. The copyright holder for this preprint (which was not certified by peer review) is the author/funder, who has granted bioRxiv a license to display the preprint in perpetuity. It is made

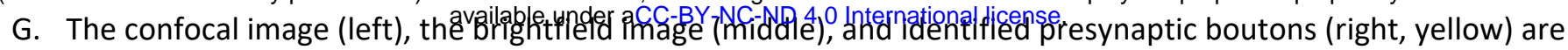
shown.

H. Identified boutons are shown for a series of slices.

I. Single-unit, multielectrode array recordings were made in the PBN or DCN in awake, head-restrained PCP2cre/Halo mice. The posterior cerebellar cortex was stimulated through a thinned skull (20 ms, red light).

J. Average firing evoked in rapidly responding PBN neurons (13/28).

K. Optically-evoked synaptic current (1 ms blue light) in a PBN neurons recorded in brain slice from a PCP2-CreChR2 mouse in the presence of NBQX and CPP.

L. Summary of the amplitudes and latencies of light evoked PC to PBN neuron synaptic currents 
bioRxiv preprint doi: https://doi.org/10.1101/2021.09.21.461236; this version posted September 23, 2021. The copyright holder for this preprint (which was not certified by peer review) is the author/funder, who has granted bioRxiv a license to display the preprint in perpetuity. It is made

$A$ Cerebellum PBN $\quad B$ available under aCC-BYENGXN 40 International license.

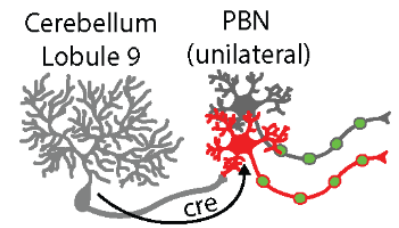

AAV1-Syn-Cre AAV1-flex-tdTomato AAV1-Synaptophysin-YFP
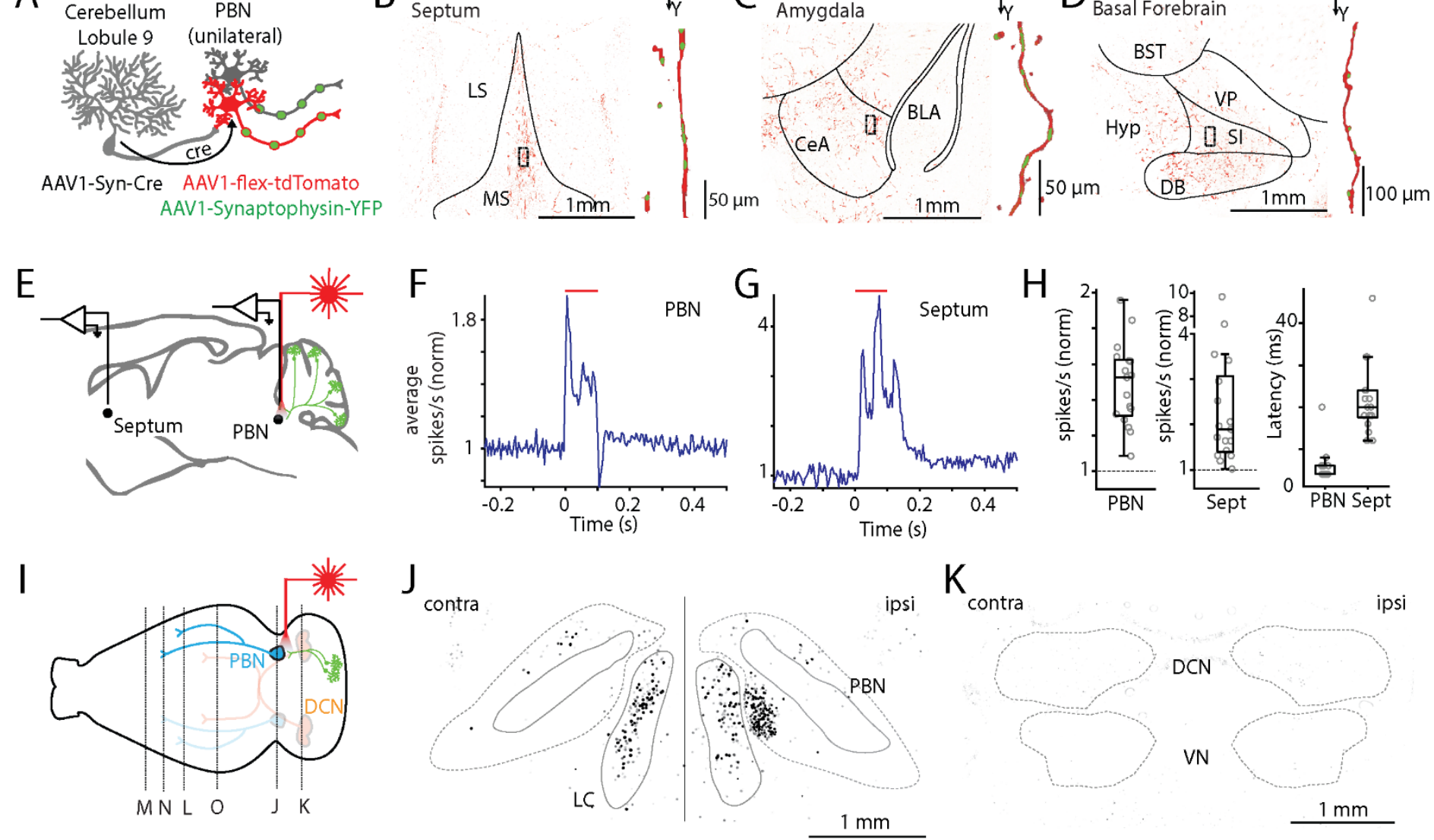

$\mathrm{K}_{\text {contra }}$

ipsi

L

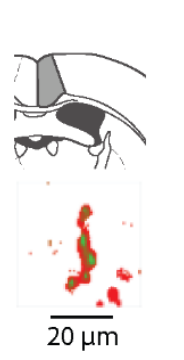

$\mathrm{N}$

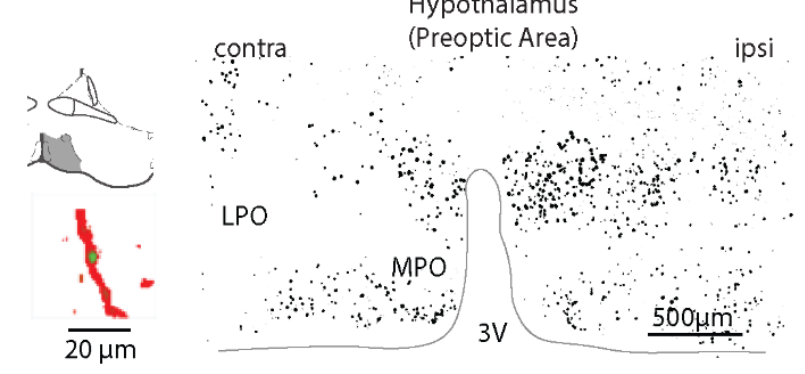

Cingulate Cortex
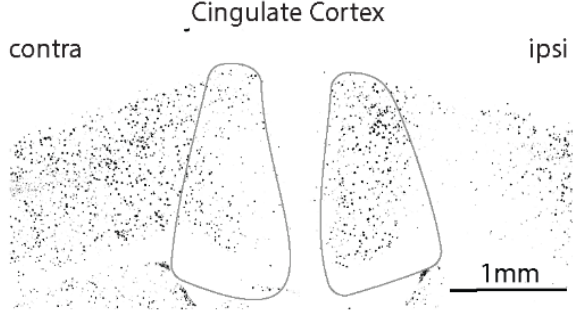

P

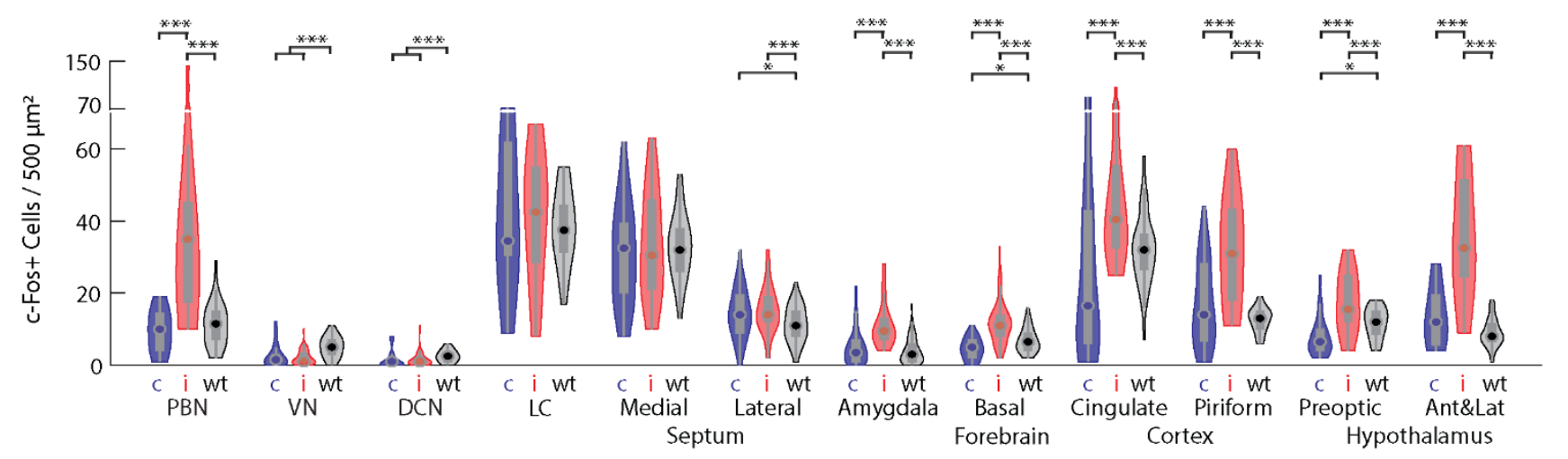




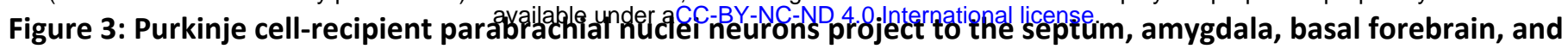
numerous other brain regions

A. An anterograde AAV-cre was injected into the posterior cerebellar vermis, while AAVs with synaptophysin-YFP and flex-tdTomato were injected into the PBN. This led to YFP labelling of the presynaptic boutons of all PBN neurons and tdT-expression restricted to PC-recipient PBN neurons.

B. left, Low magnification images of the septum.

right, high magnification image of an axon in the septum with tdTomato axons (red) and colocalized synaptophysin (green).

C. Same as B, but for the amygdala.

D. Same as $\mathbf{C}$, but for the basal forebrain.

E. Awake, head-restrained single-unit recordings from Halo/PCP2-Cre mice were made in the parabrachial using an optrode or in the septum with an optical fiber implanted in the PBN. 100 ms pulses of light were delivered through the optical fibers.

F. Average PBN neuron response ( $n=17$ cells).

G. Average septum response ( $n=17$ cells).

$\mathrm{H}$. Response magnitude and latencies for PBN and septum recordings.

I. Purkinje cell inputs to the parabrachial were unilaterally inhibited in head-restrained Halo/PCP-cre mice ( $n=4$ mice). After 3 hours of stimulation, brains were removed and stained for c-Fos.

J. c-Fos expression in the PBN was greater on the stimulated, ipsilateral PBN but not in the neighboring locus coeruleus (LC). Brachium is indicated in the solid lines.

K. c-Fos expression was not evident in the neighboring DCN or VN

L-O (left). Qualitative analysis of the injections made in A showed colabelled synaptophysin-YFP and tdTomato axons in a number of regions including but not limited to the cingulate cortex, piriform cortex, preoptic regions of the hypothalamus, and anterior/lateral regions of the hypothalamus. Top inset shows corresponding region from the stereotaxic atlas.

L-O (right). Quantification of c-Fos expression in these areas showed strong ipsilateral increases, indicative of a robust functional effect of inhibiting purkinje cell axons in the parabrachial.

P. Quantification of c-Fos expression contralateral/ipsilateral (c/i) to specific inhibition of PC axons in the parabrachial across the noted regions. Quantification of c-Fos control wildtype animals (wt) also shown for each indicated region.

CeA: central amygdala, BLA: basolateral amygdala, BST: bed nucleus of the stria terminalis, SI: substantia innominata, VP: ventral pallidum, DB: diagonal band, LS: lateral septum, MS: medial septum, Acc: nucleus accumbens, Hyp: hypothalamus, LPO: lateral preoptic nucleus, MPO: medial preoptic nucleus, 3V: $3^{\text {rd }}$ ventricle, DM: dorsomedial hypothalamic nucleus, LH: lateral hypothalamic area, VM: ventromedial hypothalamic nucleus. 
bioRxiv preprint doi: https://doi.org/10.1101/2021.09.21.461236; this version posted September 23, 2021. The copyright holder for this preprint (which was not certified by peer review) is the author/funder, who has granted bioRxiv a license to display the preprint in perpetuity. It is made
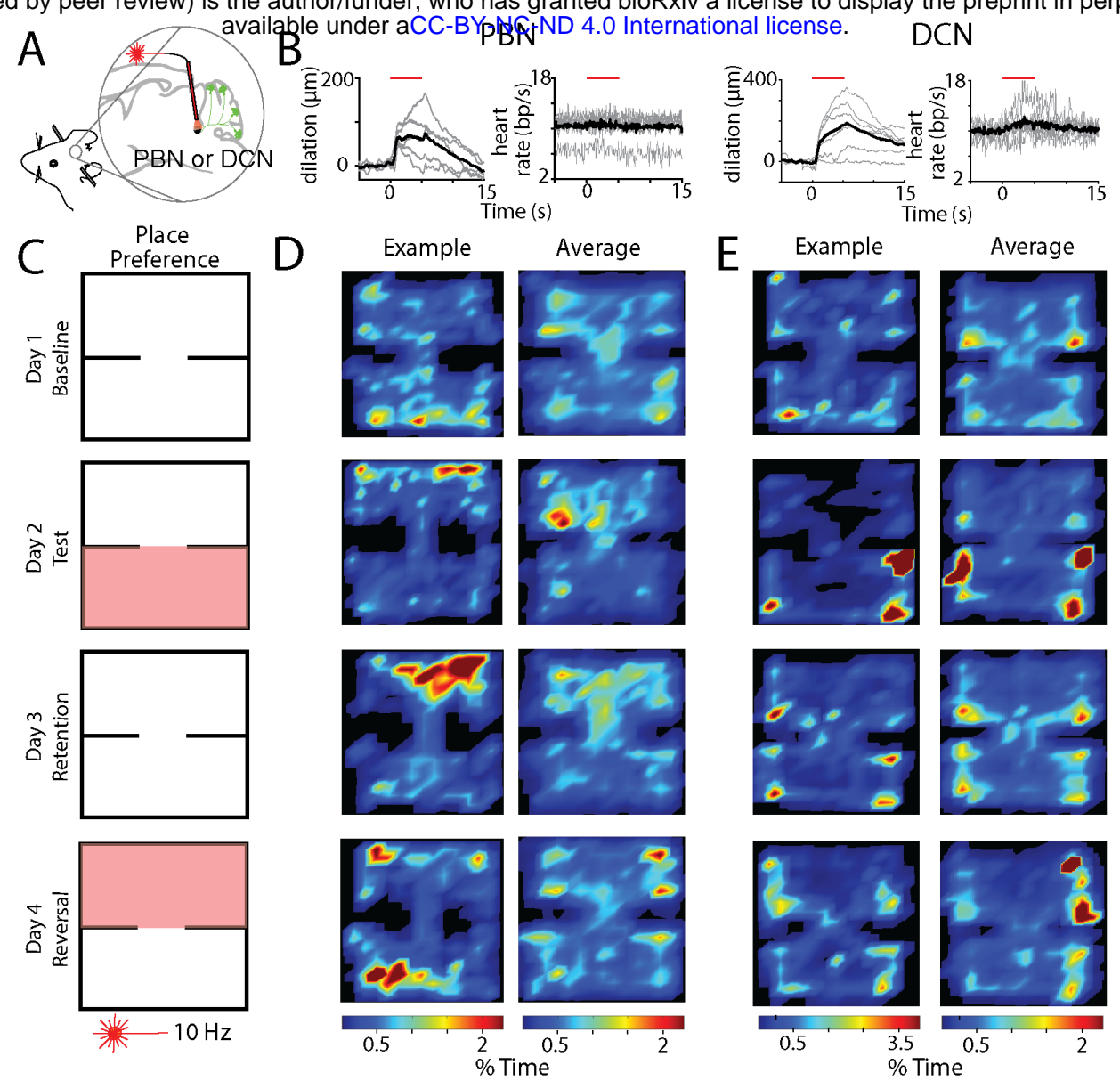

$\mathrm{F}$

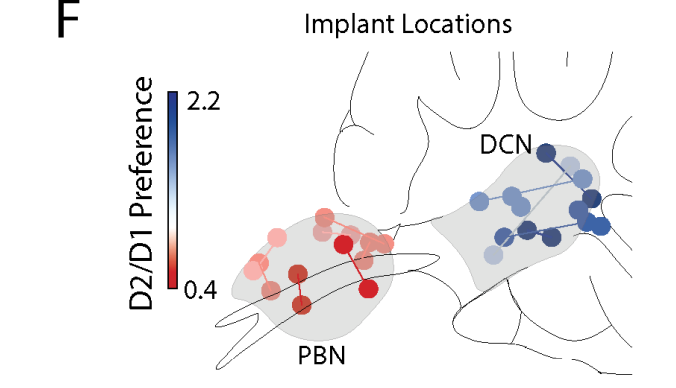

G
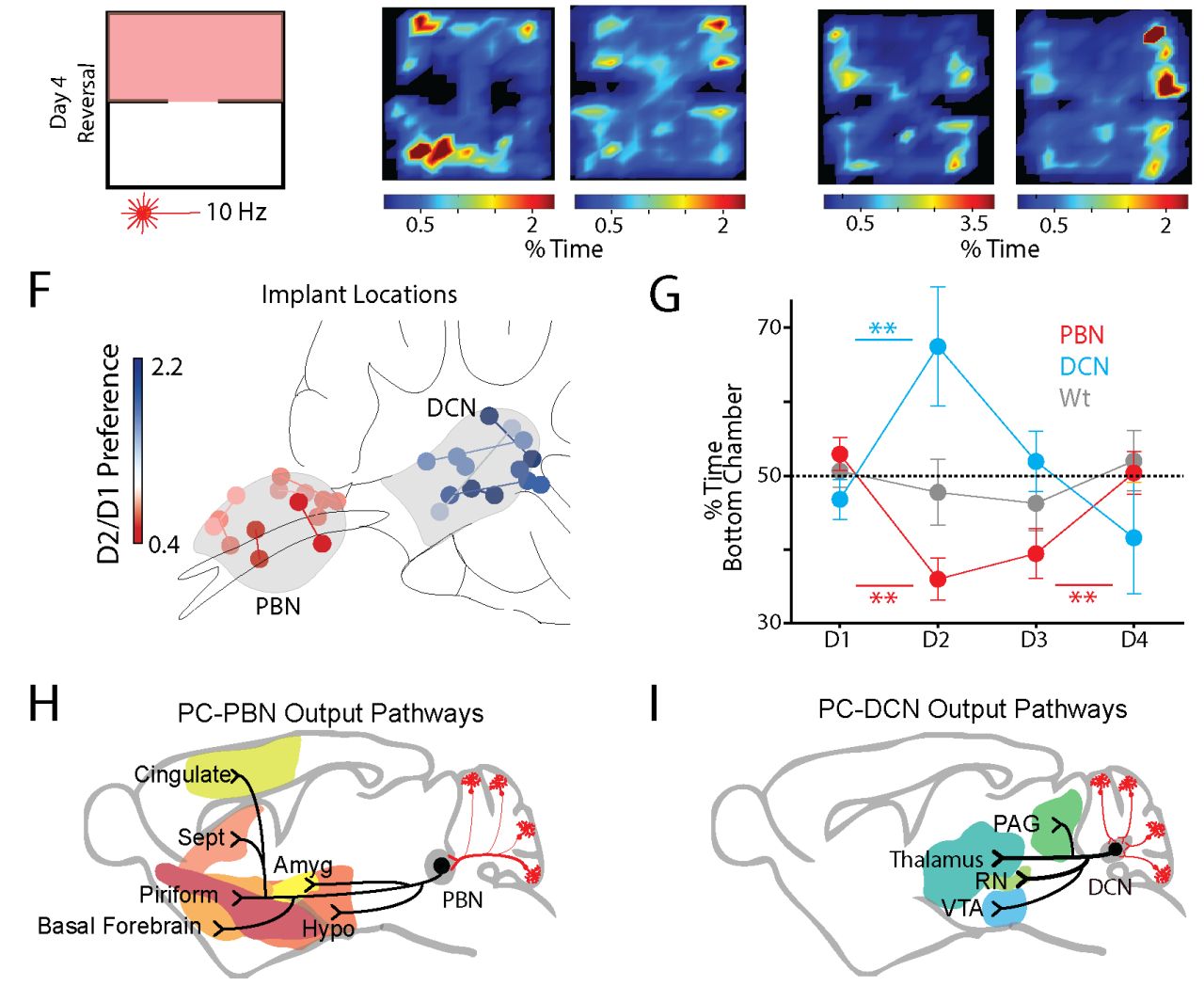

Figure 4: Cerebellar Control of Aversion and Reward.

A. Schematic shows halo/PCP-cre mice bilaterally implanted with optical fibers targeting either the PBN or DCN.

B. Illumination with $5 \mathrm{~s} 10 \mathrm{~Hz}$ train to either PBN (left) or DCN (right) to head restrained Halo/PCP-cre mice was sufficient to elicit a pupil dilation but had little influence on the heart rate.

C. Experimental configuration is shown for a two-chamber place preference test. Regions in which PC inputs to either the DCN or the PBN were optically stimulation through fibers are indicated in red. On day 1, mice moved freely without any stimulus. On day 2 , stimulation was delivered when the mouse entered the bottom chamber. On day 3 , mice again moved freely without stimulation. On day 4 , stimulation was delivered when the mouse entered the top chamber. 
bioRxiv preprint doi: https://doi.org/10.1101/2021.09.21.461236; this version posted September 23, 2021. The copyright holder for this preprint

(which was not certified by peer review) is the author/funder, who has granted bioRxiv a license to display the preprint in perpetuity. It is made

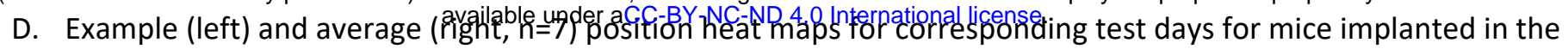
PBN.

E. Same as in D, for mice implanted in the DCN $(n=7)$.

F. Bilateral implant locations for all mice. The color indicated chamber preference on day 2 (Test/Baseline; D2/D1), with red corresponding to aversion (top chamber preference) and blue indicating attraction (bottom chamber preference). Each point on the atlas is paired to indicate positions of both optical fibers.

G. Summary of the \% time spent in the bottom chamber across all test days for PBN (red) and DCN (blue) implanted PCP2cre/Halo mice, as well as implanted wildtype mice (grey).

$\mathrm{H}$. Schematic of some of the notable forebrain/midbrain outputs for the PC-PBN pathway (shown here) and the PCDCN pathway. 

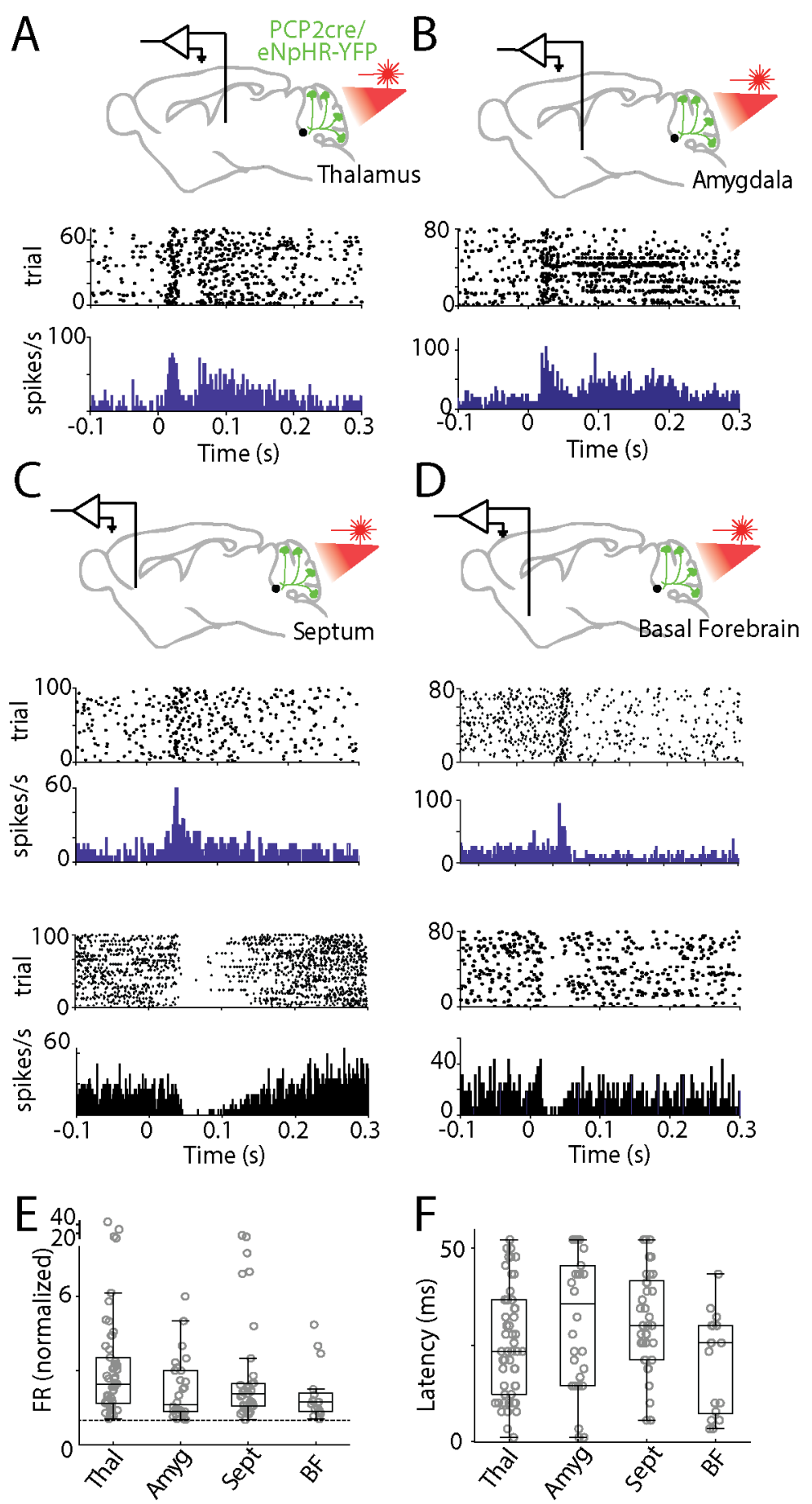

Supplemental Figure 1: Suppressing Purkinje cell firing evoked short latency responses in multiple brain regions.

Single-unit, multielectrode array recordings were made from awake, head-restrained PCP2Cre/Halo mice across several areas in the brain. Example single cell responses are shown for the thalamus (A), amygdala (B), septum (C), and basal forebrain (D). Pauses in activity after stimulation was observed in the septum and basal forebrain in a fraction of recorded cells. Example pauses are shown in black.

$\mathbf{E}+\mathbf{F}$. Box plots representing normalized change in firing rate $(\mathbf{E})$ and average latency $(\mathbf{F})$ for each region. 
A

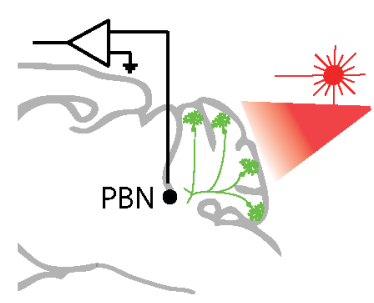

C

$\mathrm{E}$
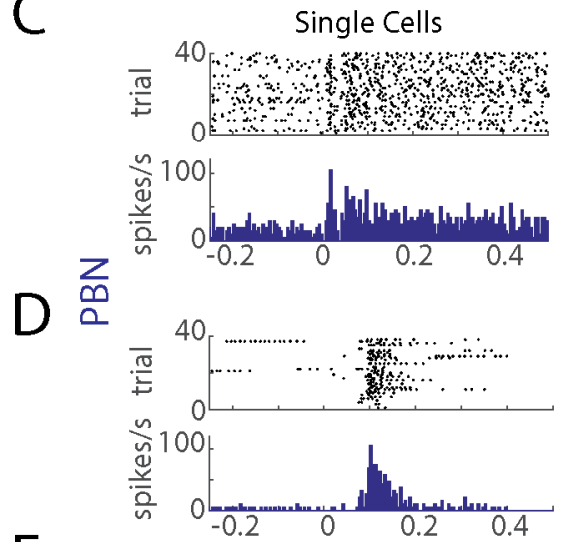

E

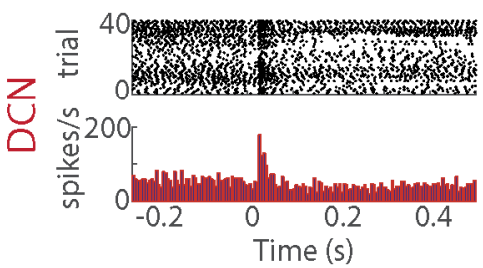

$\mathrm{F}$

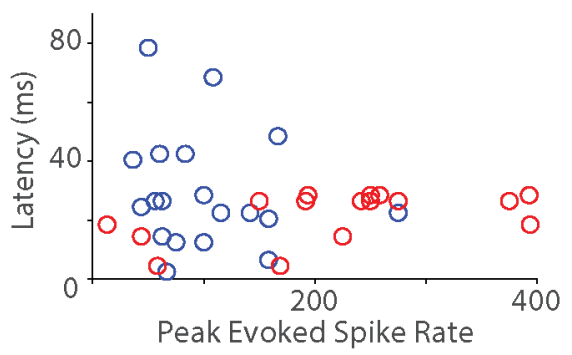

B

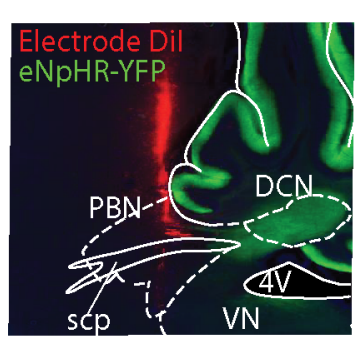

Group Averages
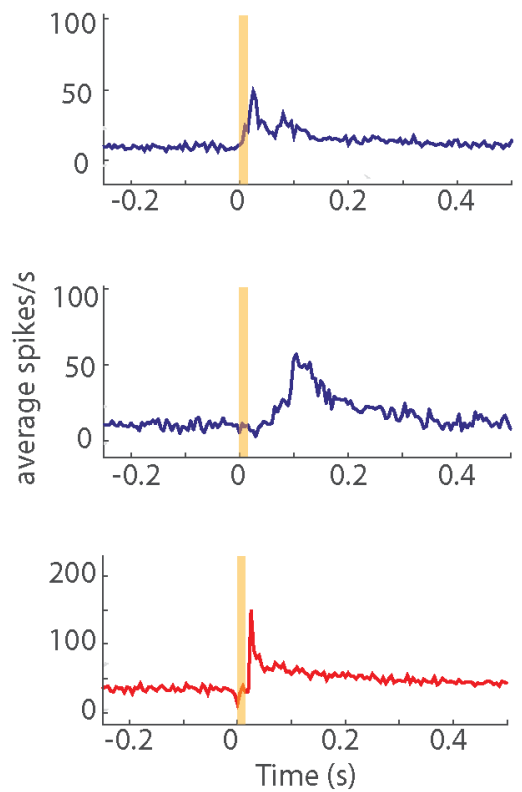

Supplemental Figure 2: Parabrachial neurons rapidly increase firing in response to Purkinje cell inhibition.

A. Single-unit, multielectrode array recordings were made in the PBN or DCN in awake, head-restrained PCP2cre/Halo mice. The posterior cerebellar cortex was stimulated through a thinned skull (20 ms, red light).

B. Recording sites were recovered by coating the silicon probe with Dil. An example electrode tract is shown. Scp: superior cerebellar peduncle, $4 \mathrm{~V}: 4^{\text {th }}$ ventricle

C. left, Firing evoked in a rapidly responding PBN neuron (<30 ms latency). right, Summary of rapidly responding PBN neurons ( $13 / 28$ neurons).

D. Same as $C$ but for slower responding PBN neurons (6/28 neurons).

E. Same as $C$ but for $D C N$ neurons (16/16 neurons).

F. Latencies of PBN neurons (blue) and DCN neurons (red) as a function of evoked firing rate. 


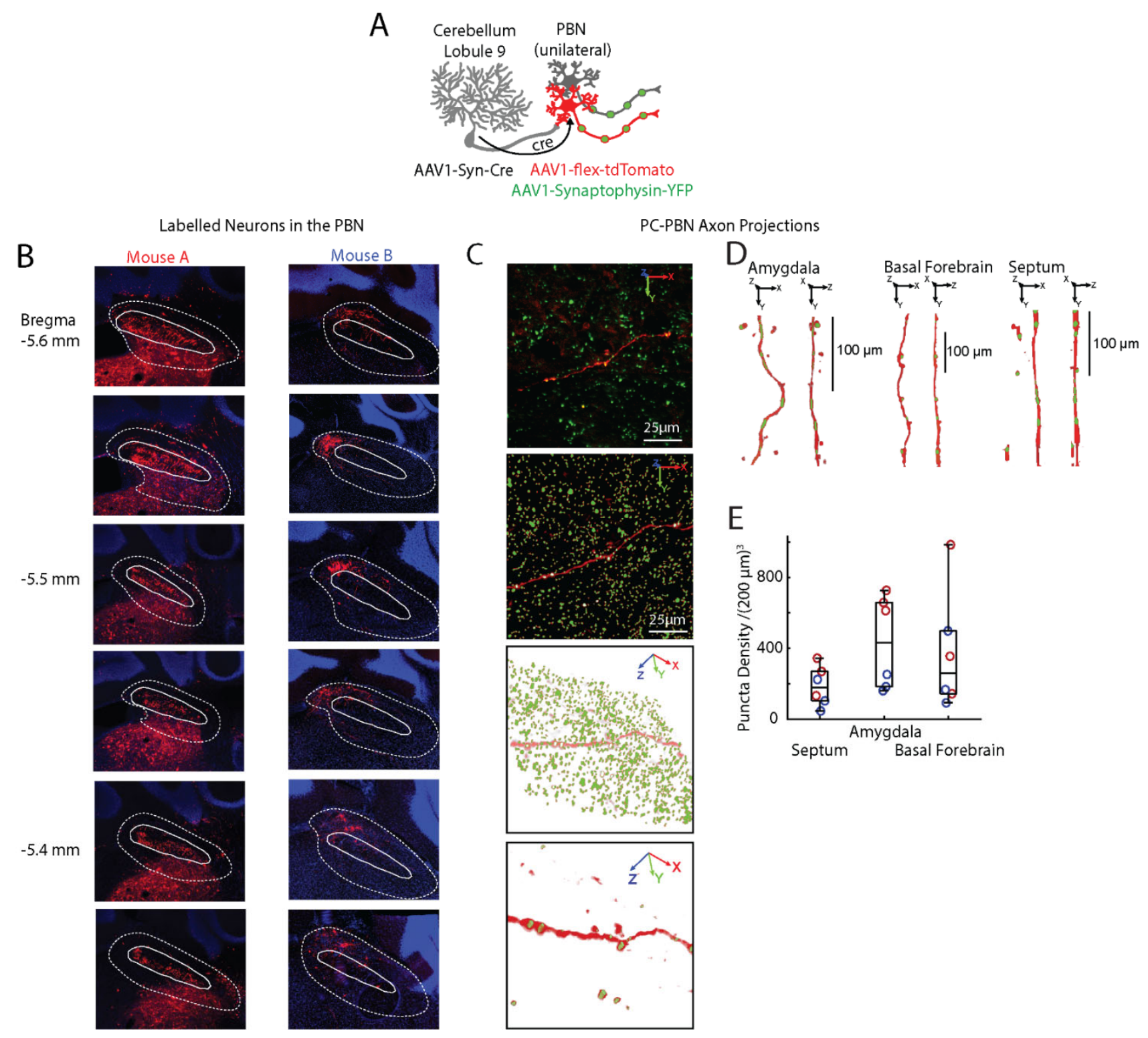

\section{Supplemental Figure 3. Labelling of PC-PBN projection pathway}

A. An anterograde AAV-cre was injected into the posterior cerebellar vermis, while AAVs with synaptophysin-YFP and flex-tdTomato were injected into the PBN. This led to YFP labelling of the presynaptic boutons of all PBN neurons and tdT-expression restricted to PC-recipient PBN neurons.

B. tdTomato expression in the parabrachial for the mice used in anatomical tracing experiments in Figure 3. These neurons were all recipients of PC axons. The extent of expression in Mouse A was significantly greater than observed in B. Solid line indicates the brachium; dotted line indicates the boundaries of the PBN.

C. To visualize PC-PBN projections and determine synaptophysin overlap, $20 \mu \mathrm{m}$ stacks of each region were taken (top panel), and synaptophysin and axon signals was segmented out using Matbots (middle panels). Only puncta associated with a tdTomato-expressing axon were displayed in the examples shown in the figure (bottom panel).

D. Example reconstructed axons for the amygdala, basal forebrain, and septum.

E. Quantification of the density of boutons labelled by both Synaptophysin-YFP and tdTomato axons. Three sections were quantified per region in the two mice whose injection sites are shown in B, with Mouse $A$ (red symbols) and Mouse B (blue symbols) 
bioRxiv preprint doi: https://doi.org/10.1101/2021.09.21.461236; this version posted September 23, 2021. The copyright holder for this preprint (which was not certified by peer review) is the author/funder, who has granted bioRxiv a license to display the preprint in perpetuity. It is made
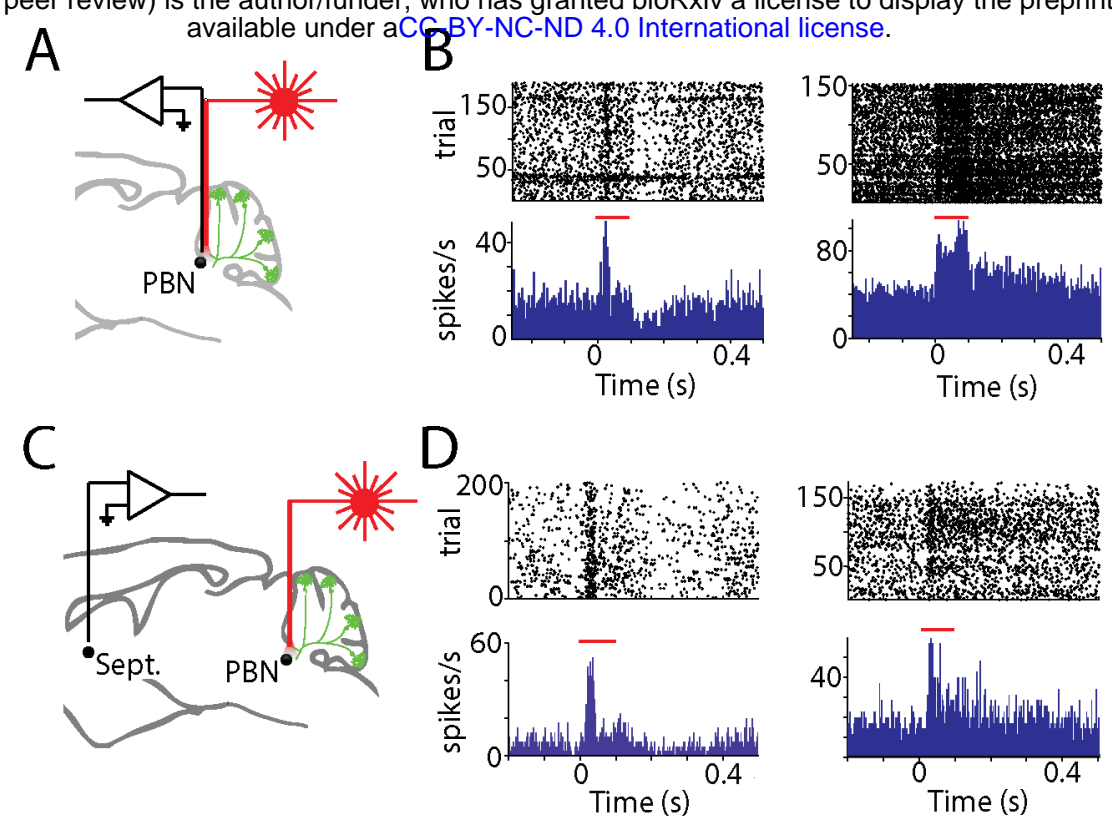

Supplemental Figure 4: Inhibiting Purkinje cell axons in the parabrachial rapidly increases activity in the parabrachial and the septum

A. Awake, head-restrained single-unit recordings in the parabrachial were made using an optrode in a Halo/PCPCre mouse.

B. Two example cells showing increases in firing during the $100 \mathrm{~ms}$ light pulse (indicated by the red line).

C. Awake, head-restrained single-unit recordings were also made in the septum while halorhodopsin expressing Purkinje cell axons were inhibited in the parabrachial.

D. Two example cells showing increases in firing during the $100 \mathrm{~ms}$ light pulse (indicated by the red line). 
bioRxiv preprint doi: https://doi.org/10.1101/2021.09.21.461236; this version posted September 23, 2021. The copyright holder for this preprint (which was not certified by peer review) is the author/funder, who has granted bioRxiv a license to display the preprint in perpetuity. It is made

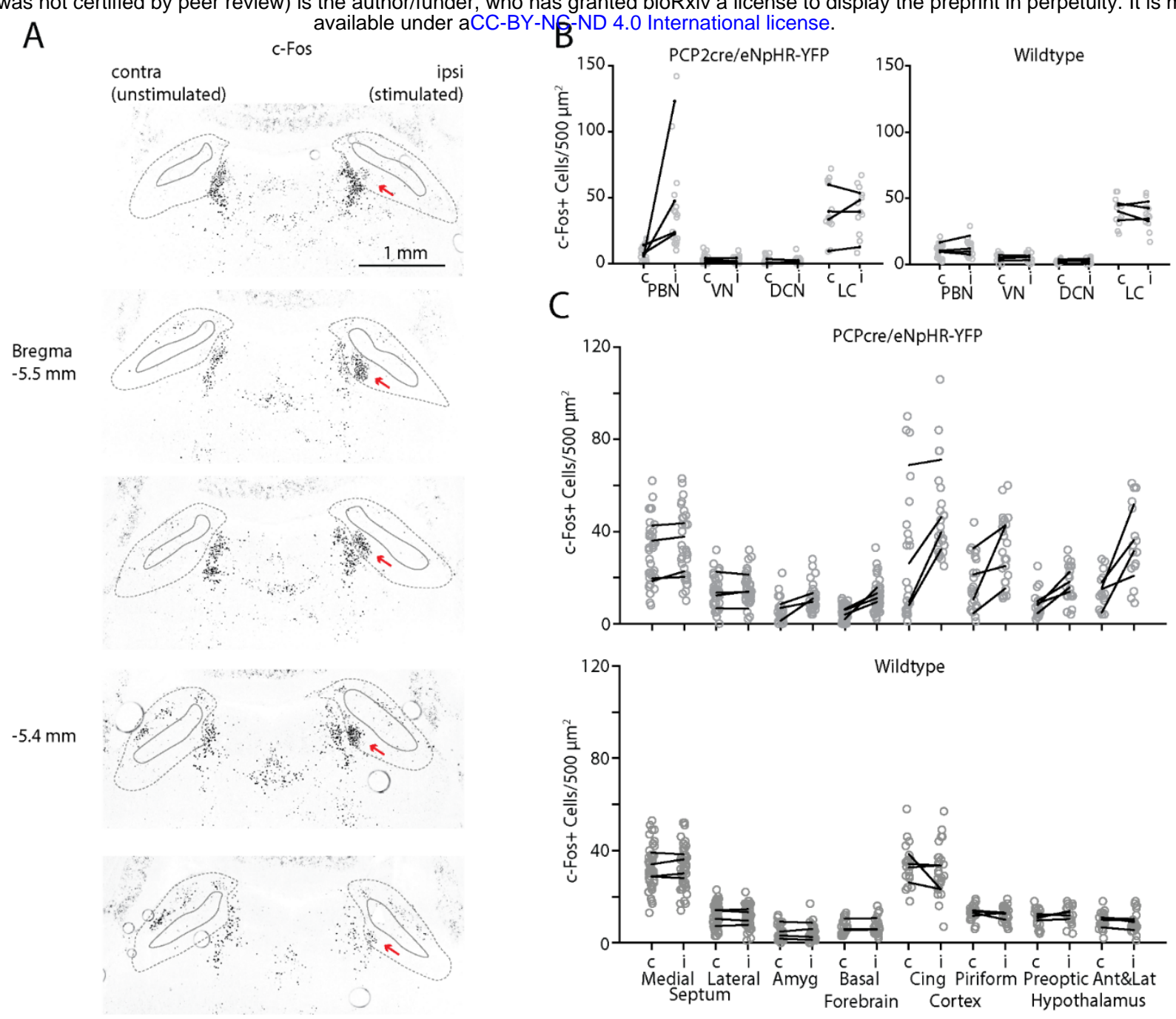

\section{Supplemental Figure 5: Upregulation of c-Fos following unilateral inhibition of PC axons in the PBN.}

A. Raw image panels for an example c-Fos stimulation experiment shown in Figure 3. Purkinje inputs to the parabrachial were inhibited by activating halorhodopsin. In this experiment, c-Fos upregulation was observed primarily in the waist of the parabrachial, on the more medial side. Unilateral upregulation was not observed elsewhere around the stimulated area (indicated by red arrow).

B. Hindbrain c-Fos densities for Halorhodopsin (left) and wildtype (right) animals. Average c-Fos+ cells per mouse plotted in black lines. Individual areas plotted in grey circles.

C. Forebrain c-Fos densities for Halorhodopsin (top) and wildtype (bottom) animals. Average c-Fos+ cells per mouse plotted in black lines. Individual areas plotted in grey circles. 
bioRxiv preprint doi: https://doi.org/10.1101/2021.09.21.461236; this version posted September 23, 2021. The copyright holder for this preprint (which was not certified by peer review) is the author/funder, who has granted bioRxiv a license to display the preprint in perpetuity. It is made
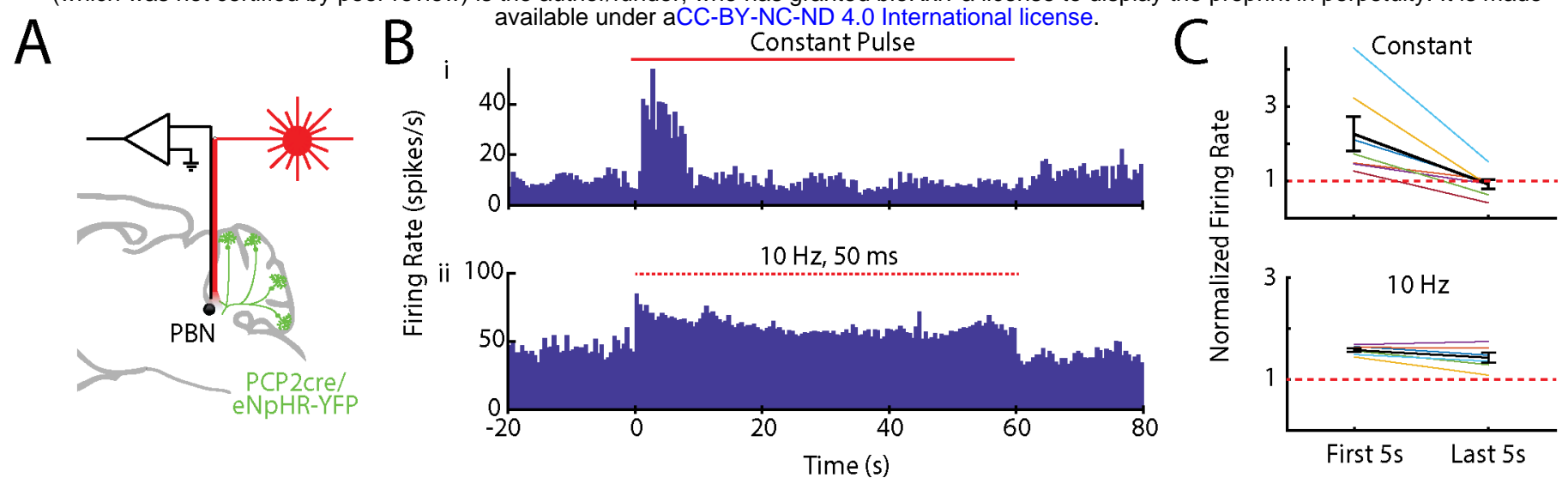

Supplemental Figure 6: Train stimulation delivered to PC-PBN axons results in stable increases in firing rate.

A. Recordings were made from PBN neurons with an optrode. Light was delivered to the immediate region with the attached optical fiber.

B. i. Example single cell response to continuous light delivered to PC-PBN axons.

ii. Example response of another cell to pulsed $(10 \mathrm{~Hz}, 50$ ms pulses) light delivered to PC-PBN axons

C. Summary data showing the firing rate in the first and last $5 \mathrm{~s}$ of the train for continuous (top) or pulsed (bottom) trains. 
bioRxiv preprint doi: https://doi.org/10.1101/2021.09.21.461236; this version posted September 23, 2021. The copyright holder for this preprint (which was not certified by peer review) is the author/funder, who has granted bioRxiv a license to display the preprint in perpetuity. It is made available under aCC-BY-NC-ND 4.0 International license.
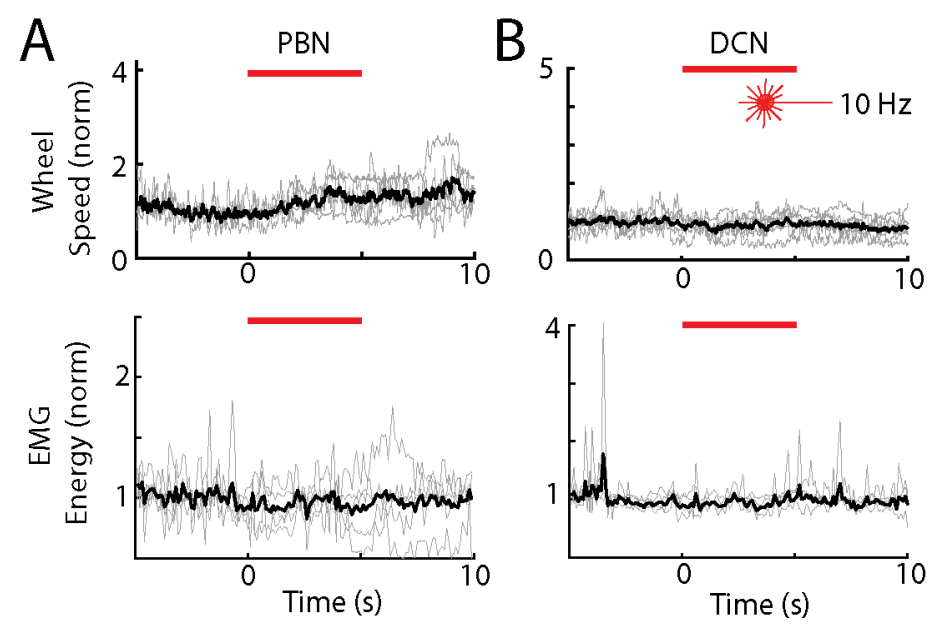

Supplemental Figure 7: Stimulation of PC-PBN axons or PC-DCN axons does not elicit motor activity.

A. Halo/PCP-cre mice with optical fiber implants targeting their PBN were subcutaneously implanted with wires in their backs to measure a field EMG $(n=5)$. Mice were head restrained over a freely moving wheel. Speed of the wheel (top) and field EMG (bottom) during stimulation $(10 \mathrm{~Hz}, 5 \mathrm{~s})$, were measured $(n=5)$.

B. Wheel speed $(n=7)$ and EMG $(n=4)$ as in $A$, except for mice implanted in the DCN 
bioRxiv preprint doi: https://doi.org/10.1101/2021.09.21.461236; this version posted September 23, 2021. The copyright holder for this preprint (which was not certified by peer review) is the author/funder, who has granted bioRxiv a license to display the preprint in perpetuity. It is made
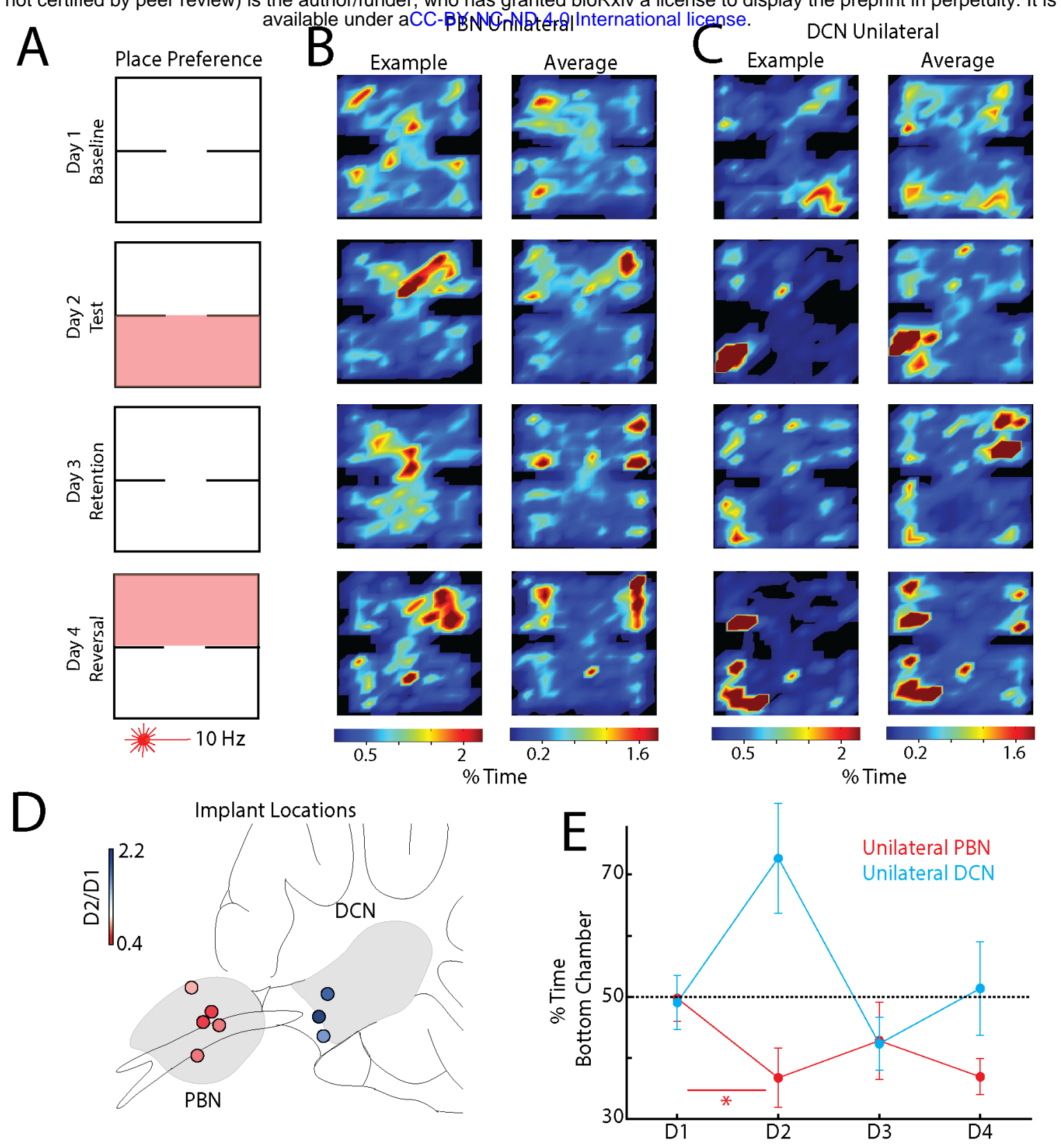

Supplemental Figure 8: Place preference for animals with one optical fiber implanted correctly

A. Attempted bilateral implants often resulted in one optical fiber implanted in a target region, and another implanted completely elsewhere devoid of halorhodopsin expression. We examined these mice's behavior in the place preference protocol as in Figure 4

B. Example (left) and average (right) position heatmaps for corresponding days of the place preference protocol for mice with unilateral implants in the $\operatorname{PBN}(B, n=5)$ and unilateral implants in the $\operatorname{DCN}(\mathbf{C}, n=3)$

D. Implant locations for all mice with color indicating bottom chamber preference (Test/Baseline; D2/D1).

E. Summary of the \% time spent in the bottom chamber across all test days for PBN (red) and DCN (blue) unilaterally implanted PCP2cre/Halo mice 
Table 1: c-Fos Statistics

\begin{tabular}{|c|c|c|c|c|c|}
\hline Figure & ROls & Animals & $\begin{array}{l}\text { Average } \\
\text { (mean) }\end{array}$ & S.E.M. & Statistics \\
\hline \multicolumn{6}{|l|}{$\begin{array}{l}\text { Figure 3P \& Supp } \\
\text { Figure 5B: }\end{array}$} \\
\hline PBN (halo) & $\begin{array}{l}\text { Contra: } 16 \\
\text { Ipsi: } 17\end{array}$ & 4 & $\begin{array}{l}9.5 \\
40.53\end{array}$ & $\begin{array}{l}1.46 \\
8.46\end{array}$ & $\begin{array}{l}\text { One-sided Wilcoxon rank sum } \\
p=1.44 \mathrm{e}-5 ; \mathrm{w}=155.5\end{array}$ \\
\hline PBN (wt) & $\begin{array}{l}42 \text { total } \\
(21 / 21 \\
\text { contra/ipsi) }\end{array}$ & 4 & 11.07 & 0.87 & $\begin{array}{l}\text { Wilcoxon rank sum } \\
\text { vs. contra halo } p=0.3928 ; w=1289 \\
\text { vs. ipsi halo } p=8.2 e-7 ; w=965.5\end{array}$ \\
\hline VN (halo) & $\begin{array}{l}\text { Contra: } 26 \\
\text { Ipsi: } 45\end{array}$ & 4 & $\begin{array}{l}2.73 \\
2.18\end{array}$ & $\begin{array}{l}0.63 \\
0.31\end{array}$ & $\begin{array}{l}\text { One-sided Wilcoxon rank sum } \\
p=0.5797 ; w=952\end{array}$ \\
\hline VN (wt) & $\begin{array}{l}32 \text { total } \\
(16 / 16 \\
\text { contra/ipsi) }\end{array}$ & 4 & 5.03 & 0.53 & $\begin{array}{l}\text { Wilcoxon rank sum } \\
\text { vs. contra halo } p=0.003 ; w=1135 \\
\text { vs. ipsi halo } p=2.8 e-5 ; w=1650\end{array}$ \\
\hline DCN (halo) & $\begin{array}{l}\text { Contra: } 30 \\
\text { Ipsi: } 40\end{array}$ & 4 & $\begin{array}{l}1.6 \\
1.5\end{array}$ & $\begin{array}{l}0.45 \\
0.31\end{array}$ & $\begin{array}{l}\text { One-sided Wilcoxon rank sum } \\
p=0.1641 ; w=986\end{array}$ \\
\hline DCN (wt) & $\begin{array}{l}32 \text { total } \\
(16 / 16 \\
\text { contra/ipsi) }\end{array}$ & 4 & 2.53 & 0.29 & $\begin{array}{l}\text { Wilcoxon rank sum } \\
\text { vs. contra halo } p=0.003 ; w=1214.5 \\
\text { vs. ipsi halo } p=1.5 e-3 ; w=1440.5\end{array}$ \\
\hline LC (halo) & $\begin{array}{l}\text { Contra: } 12 \\
\text { Ipsi: } 12\end{array}$ & 4 & $\begin{array}{l}40.25 \\
41\end{array}$ & $\begin{array}{l}6.02 \\
5.28\end{array}$ & $\begin{array}{l}\text { One-sided Wilcoxon rank sum } \\
p=0.42 ; w=146\end{array}$ \\
\hline LC (wt) & $\begin{array}{l}24 \text { total } \\
(12 / 12 \\
\text { contra/ipsi) }\end{array}$ & 4 & 38.46 & 2.14 & $\begin{array}{l}\text { Wilcoxon rank sum } \\
\text { vs. contra halo } p=0.46 ; w=1214.5 \\
\text { vs. ipsi halo } p=0.95 ; w=446.5\end{array}$ \\
\hline \multicolumn{6}{|l|}{$\begin{array}{l}\text { Figure } 3 P \text { \& Supp } \\
\text { Figure } 5 C \text { : }\end{array}$} \\
\hline $\begin{array}{l}\text { Medial Septum } \\
\text { (halo) }\end{array}$ & $\begin{array}{l}\text { Contra: } 36 \\
\text { Ipsi: } 34\end{array}$ & 4 & $\begin{array}{l}30.61 \\
33.32\end{array}$ & $\begin{array}{l}2.29 \\
2.50\end{array}$ & $\begin{array}{l}\text { One-sided Wilcoxon rank sum } \\
p=0.26 ; w=1264\end{array}$ \\
\hline $\begin{array}{l}\text { Medial Septum } \\
\text { (wildtype) }\end{array}$ & $\begin{array}{l}96 \text { total } \\
(48 / 48 \\
\text { contra/ipsi) }\end{array}$ & 4 & 32.90 & 0.93 & $\begin{array}{l}\text { Wilcoxon rank sum } \\
\text { vs. contra halo } p=0.29 ; w=2188 \\
\text { vs. ipsi halo } p=0.77 ; w=2171\end{array}$ \\
\hline $\begin{array}{l}\text { Lateral Septum } \\
\text { (halo) }\end{array}$ & $\begin{array}{l}\text { Contra: } 40 \\
\text { Ipsi: } 42\end{array}$ & 4 & $\begin{array}{l}14.33 \\
15.29\end{array}$ & $\begin{array}{l}1.08 \\
0.98\end{array}$ & $\begin{array}{l}\text { One-sided Wilcoxon rank sum } \\
p=0.29 ; w=1804\end{array}$ \\
\hline $\begin{array}{l}\text { Lateral Septum } \\
\text { (wildtype) }\end{array}$ & 96 total & 4 & 11.46 & 0.50 & $\begin{array}{l}\text { Wilcoxon rank sum } \\
\text { vs. contra halo } p=0.02 ; w=3168\end{array}$ \\
\hline
\end{tabular}


bioRxiv preprint doi: https://doi.org/10.1101/2021.09.21.461236; this version posted September 23, 2021. The copyright holder for this preprint (which was not certified by peer review) is the author/funder, who has granted bioRxiv a license to display the preprint in perpetuity. It is made

\begin{tabular}{|c|c|c|c|c|c|}
\hline & $\begin{array}{l}(48 / 48 \\
\text { contra/ipsi) }\end{array}$ & vaila & $C-B Y$ & 4.01 & alsicenssi halo $p=6.8 e-4 ; w=3597$ \\
\hline Amygdala (halo) & $\begin{array}{l}\text { Contra: } 28 \\
\text { Ipsi: } 32\end{array}$ & 3 & $\begin{array}{l}5.04 \\
10.94\end{array}$ & $\begin{array}{l}0.96 \\
1.05\end{array}$ & $\begin{array}{l}\text { One-sided Wilcoxon rank sum } \\
p=7.53 e-6 ; w=562\end{array}$ \\
\hline $\begin{array}{l}\text { Amygdala } \\
\text { (wildtype) }\end{array}$ & $\begin{array}{l}60 \text { total } \\
(30 / 30 \\
\text { contra/ipsi) }\end{array}$ & 4 & 4.03 & 0.46 & $\begin{array}{l}\text { Wilcoxon rank sum } \\
\text { vs. contra halo } p=0.57 ; w=1308 \\
\text { vs. ipsi halo } p=3.1 e-9 ; w=2207\end{array}$ \\
\hline $\begin{array}{l}\text { Basal Forebrain } \\
\text { (halo) }\end{array}$ & $\begin{array}{l}\text { Contra: } 58 \\
\text { Ipsi: } 54\end{array}$ & 4 & $\begin{array}{l}4.67 \\
11.85\end{array}$ & $\begin{array}{l}0.39 \\
0.81\end{array}$ & $\begin{array}{l}\text { One-sided Wilcoxon rank sum } \\
p=1.26 e-12 ; w=2077\end{array}$ \\
\hline $\begin{array}{l}\text { Basal Forebrain } \\
\text { (wildtype) }\end{array}$ & $\begin{array}{l}48 \text { total } \\
\text { ( } 24 / 24 \\
\text { contra/ipsi) }\end{array}$ & 4 & 6.96 & 0.48 & $\begin{array}{l}\text { Wilcoxon rank sum } \\
\text { vs. contra halo } p=0.0015 ; w=2605 \\
\text { vs. ipsi halo } p=1.95 e-6 ; w=3489\end{array}$ \\
\hline $\begin{array}{l}\text { Cingulate Cortex } \\
\text { (halo) }\end{array}$ & $\begin{array}{l}\text { Contra: } 22 \\
\text { Ipsi: } 24\end{array}$ & 4 & $\begin{array}{l}29.91 \\
47.33\end{array}$ & $\begin{array}{l}6.12 \\
4.15\end{array}$ & $\begin{array}{l}\text { One-sided Wilcoxon rank sum } \\
p=0.0069 ; w=404.5\end{array}$ \\
\hline $\begin{array}{l}\text { Cingulate Cortex } \\
\text { (wildtype) }\end{array}$ & $\begin{array}{l}48 \text { total } \\
(24 / 24 \\
\text { contra/ipsi) }\end{array}$ & 4 & 32.4 & 1.45 & $\begin{array}{l}\text { Wilcoxon rank sum } \\
\text { vs. contra halo } p=0.99 ; w=2605 \\
\text { vs. ipsi halo } p=9.75 e-7 ; w=3489\end{array}$ \\
\hline $\begin{array}{l}\text { Piriform Cortex } \\
\text { (halo) }\end{array}$ & $\begin{array}{l}\text { Contra: } 25 \\
\text { Ipsi: } 25\end{array}$ & 4 & $\begin{array}{l}16.96 \\
31.80\end{array}$ & $\begin{array}{l}2.34 \\
2.95\end{array}$ & $\begin{array}{l}\text { One-sided Wilcoxon rank sum } \\
p=3.79 e-4 ; w=463.5\end{array}$ \\
\hline $\begin{array}{l}\text { Piriform Cortex } \\
\text { (wildtype) }\end{array}$ & $\begin{array}{l}48 \text { total } \\
(24 / 24 \\
\text { contra/ipsi) }\end{array}$ & 4 & 12.60 & 0.49 & $\begin{array}{l}\text { Wilcoxon rank sum } \\
\text { vs. contra halo } p=0.44 ; w=991 \\
\text { vs. ipsi halo } p=7.04 e-8 ; w=1388\end{array}$ \\
\hline $\begin{array}{l}\text { Preoptic } \\
\text { Hypothalamus } \\
\text { (halo) }\end{array}$ & $\begin{array}{l}\text { Contra: } 16 \\
\text { Ipsi: } 16\end{array}$ & 4 & $\begin{array}{l}5.88 \\
15.31\end{array}$ & $\begin{array}{l}0.68 \\
2.01\end{array}$ & $\begin{array}{l}\text { One-sided Wilcoxon rank sum } \\
p=6.62 \mathrm{e}-5 ; \mathrm{w}=162.5\end{array}$ \\
\hline $\begin{array}{l}\text { Preoptic } \\
\text { Hypothalamus } \\
\text { (wildtype) }\end{array}$ & $\begin{array}{l}32 \text { total } \\
(16 / 16 \\
\text { contra/ipsi) }\end{array}$ & 4 & 11.69 & 0.75 & $\begin{array}{l}\text { Wilcoxon rank sum } \\
\text { vs. contra halo } p=0.004 ; w=378.5 \\
\text { vs. ipsi halo } p=0.02 ; w=654\end{array}$ \\
\hline $\begin{array}{l}\text { Anterior \& Lateral } \\
\text { Hypothalamus } \\
\text { (halo) }\end{array}$ & $\begin{array}{l}\text { Contra: } 16 \\
\text { Ipsi: } 16\end{array}$ & 4 & $\begin{array}{l}13.31 \\
35.06\end{array}$ & $\begin{array}{l}2.02 \\
4.29\end{array}$ & $\begin{array}{l}\text { One-sided Wilcoxon rank sum } \\
p=1.58 \mathrm{e}-4 ; \mathrm{w}=168\end{array}$ \\
\hline $\begin{array}{l}\text { Anterior \& Lateral } \\
\text { Hypothalamus } \\
\text { (wildtype) }\end{array}$ & $\begin{array}{l}44 \text { total } \\
\text { ( } 22 / 22 \\
\text { contra/ipsi) }\end{array}$ & 4 & 9.046 & 0.60 & $\begin{array}{l}\text { Wilcoxon rank sum } \\
\text { vs. contra halo } p=0.11 ; w=584.5 \\
\text { vs. ipsi halo } p=1.25 e-7 ; w=804\end{array}$ \\
\hline
\end{tabular}


bioRxiv preprint doi: https://doi.org/10.1101/2021.09.21.461236; this version posted September 23, 2021. The copyright holder for this preprint (which was not certified by peer review) is the author/funder, who has granted bioRxiv a license to display the preprint in perpetuity. It is made Table 2: Heart Rate Statistics available under aCC-BY-NC-ND 4.0 International license.

\begin{tabular}{l|l|l|l|l|l} 
Figure & Animals & Comparison & $\begin{array}{l}\text { Mean } \\
\text { Norm. } \\
\text { Evoked HR }\end{array}$ & S.E.M. & Statistics \\
\hline Figure 4B+C: & 7 & $\begin{array}{l}\text { Evoked Heart } \\
\text { rate vs. } 1\end{array}$ & 1.123 & 0.077 & $\begin{array}{l}\text { Wilcoxon signed rank } \\
p=0.0078 ; w=28 ; \text { one-tailed }\end{array}$ \\
PCN & 7 & $\begin{array}{l}\text { Evoked Heart } \\
\text { rate vs. } 1\end{array}$ & 1.016 & 0.008 & $p=0.078 ; \mathrm{w}=23 ;$ one-tailed
\end{tabular}

Table 3: Place Preference Statistics

\begin{tabular}{|c|c|c|c|c|c|}
\hline Figure & Animals & Comparison & Mean & S.E.M. & Statistics \\
\hline \multicolumn{6}{|l|}{ Figure 4: } \\
\hline \multirow[t]{3}{*}{ PBN } & 7 & $\begin{array}{l}\text { D1 vs } \\
\text { D2 }\end{array}$ & $\begin{array}{l}0.53 \\
0.36\end{array}$ & $\begin{array}{l}0.02 \\
0.03\end{array}$ & $\begin{array}{l}\text { Wilcoxon signed rank } \\
p=0.0078 ; w=28 ; \text { one-tailed }\end{array}$ \\
\hline & & $\begin{array}{l}\text { D2 vs } \\
\text { D3 }\end{array}$ & 0.40 & 0.03 & $\mathrm{p}=0.58 ; \mathrm{w}=10 ;$ two-tailed \\
\hline & & $\begin{array}{l}\text { D3 vs } \\
\text { D4 }\end{array}$ & 0.50 & 0.03 & $p=0.0078 ; w=0 ;$ one-tailed \\
\hline \multirow[t]{3}{*}{ DCN } & 7 & $\begin{array}{l}\text { D1 vs } \\
\text { D2 }\end{array}$ & $\begin{array}{l}0.47 \\
0.67\end{array}$ & $\begin{array}{l}0.03 \\
0.08\end{array}$ & $p=0.0078 ; w=0 ;$ one-tailed \\
\hline & & $\begin{array}{l}\text { D2 vs } \\
\text { D3 }\end{array}$ & 0.5194 & 0.04 & $p=0.156 ; w=23 ;$ two-tailed \\
\hline & & $\begin{array}{l}\text { D3 vs } \\
\text { D4 }\end{array}$ & 0.4161 & 0.08 & $p=0.23 ; w=19 ;$ one-tailed \\
\hline \multirow[t]{3}{*}{ Wildtype } & 9 & $\begin{array}{l}\text { D1 vs } \\
\text { D2 }\end{array}$ & $\begin{array}{l}0.51 \\
0.48\end{array}$ & $\begin{array}{l}0.02 \\
0.04\end{array}$ & $p=0.65 ; w=27 ;$ two-tailed \\
\hline & & $\begin{array}{l}\text { D2 vs } \\
\text { D3 }\end{array}$ & 0.46 & 0.04 & $\mathrm{p}=0.82 ; \mathrm{w}=25 ;$ two-tailed \\
\hline & & $\begin{array}{l}\text { D3 vs } \\
\text { D4 }\end{array}$ & 0.52 & 0.04 & $p=0.36 ; w=14 ;$ two-tailed \\
\hline
\end{tabular}


bioRxiv preprint doi: https://doi.org/10.1101/2021.09.21.461236; this version posted September 23, 2021. The copyright holder for this preprint (which was not certified by peer review) is the author/funder, who has granted bioRxiv a license to display the preprint in perpetuity. It is made

\section{Figure 4}

PBN:

D1

\begin{tabular}{l|l} 
D2 & 7 \\
D3 & 7 \\
D4 & 7
\end{tabular}

D1

D2

D3

D4

DCN:

D1

D2

D3

D4

D1

D2

D3

D4

Wt:

D1

D2

D3

D4

\section{Supplemental}

Figure 8:

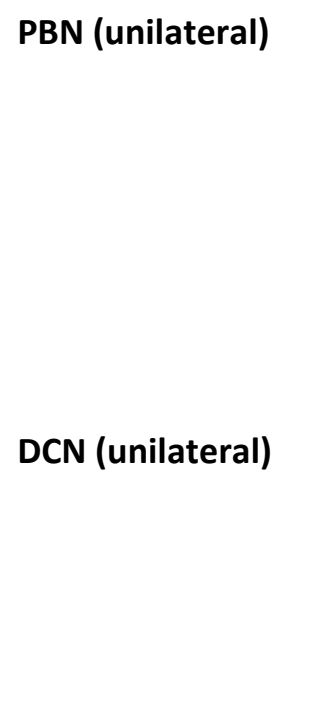

5

3 available under aCC-BY-NC-ND 4.0 International license.

\section{Wilcoxon signed rank}

$\mathrm{p}=0.14 ; \mathrm{w}=21$; two-tailed

$p=0.0078 ; w=0 ;$ one-tailed

$\mathrm{p}=0.0156 ; \mathrm{w}=1 ;$ one-tailed

$\mathrm{p}=1 ; \mathrm{w}=14 ;$ two-tailed

Wilcoxon rank sum

Vs. wildtype

$p=0.47 ; w=67 ;$ two-tailed

$\mathrm{p}=0.02 ; \mathrm{w}=40$; one-tailed

$p=0.14 ; w=49 ;$ one-tailed

$\mathrm{p}=0.61 ; \mathrm{w}=54$; two-tailed

Wilcoxon signed rank

Vs. chance

0.47

0.03

0.67

0.08

0.5194

0.04

\begin{tabular}{l|l}
0.4161 & 0.08
\end{tabular}

Vs. wildtype

$p=0.38 ; w=8 ;$ two-tailed

$p=0.0391 ; w=25$; one-tailed

$p=0.41 ; w=16$; one-tailed

$\mathrm{p}=0.58 ; \mathrm{w}=10$; two-tailed

Wilcoxon rank sum

$p=0.408 ; w=51 ;$ two-tailed

$p=0.0708 ; w=74 ;$ one-tailed

$p=0.1755 ; w=69 ;$ one-tailed

$p=0.35 ; w=50 ;$ two-tailed

Wilcoxon signed rank

Vs. chance

(0.5)

0.51

0.02

0.04

0.48

0.04

\begin{tabular}{l|l}
0.46 & 0.04 \\
0.52 & 0.04
\end{tabular}

$\mathrm{p}=0.82 ; \mathrm{w}=20$; two-tailed

$p=0.91 ; w=21 ;$ two-tailed

$p=0.43 ; w=15 ;$ two-tailed

$\mathrm{p}=0.65 ; \mathrm{w}=27$; two-tailed

Wilcoxon signed rank

D2

0.368

0.048

$p=0.0313 ; w=15$; one-tailed

D2 vs

D3

0.428

0.063

$p=0.625 ; w=5 ;$ two-tailed

D3 vs

D4

0.369

0.294

$p=0.906 ; w=12 ;$ one-tailed

D1 vs

0.491

0.051

D2

0.727

0.105

$p=0.125 ; w=0 ;$ one-tailed

D2 vs

D3 
bioRxiv preprint doi: https://doi.org/10.1101/2021.09.21.461236; this version posted September 23, 2021. The copyright holder for this preprint (which was not certified by peer review) is the author/funder, who has granted bioRxiv a license to display the preprint in perpetuity. It is made

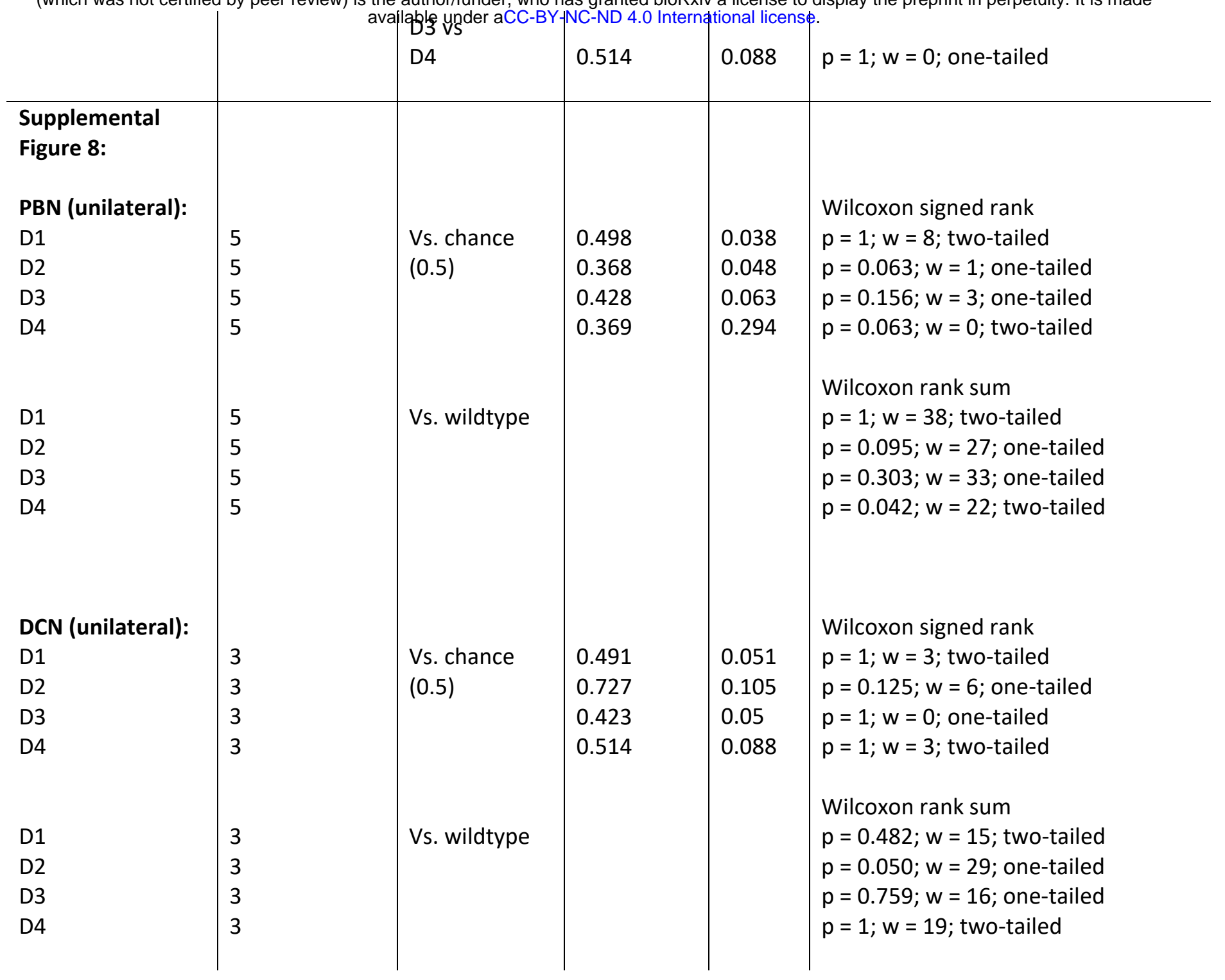

